\title{
Civil Aircraft for the regular investigation of the atmosphere based on an instrumented container: The new CARIBIC system
}

\author{
C. A. M. Brenninkmeijer ${ }^{1}$, P. Crutzen ${ }^{1}$, F. Boumard ${ }^{5}$, T. Dauer ${ }^{2}$, B. Dix ${ }^{3}$, R. Ebinghaus ${ }^{4}$, D. Filippi ${ }^{5}$, H. Fischer ${ }^{6}$, \\ H. Franke ${ }^{7}$, U. Frieß ${ }^{3}$, J. Heintzenberg ${ }^{8}$, F. Helleis ${ }^{1}$, M. Hermann ${ }^{8}$, H. H. Kock ${ }^{4}$, C. Koeppel ${ }^{1}$, J. Lelieveld ${ }^{1}$, \\ M. Leuenberger ${ }^{9}$, B. G. Martinsson ${ }^{10}$, S. Miemczyk ${ }^{11}$, H. P. Moret ${ }^{9}$, H. N. Nguyen ${ }^{10}$, P. Nyfeler ${ }^{9}$, D. Oram ${ }^{12}$, \\ D. O'Sullivan ${ }^{12}$, S. Penkett ${ }^{12}$, U. Platt ${ }^{3}$, M. Pupek ${ }^{1}$, M. Ramonet ${ }^{5}$, B. Randa ${ }^{1}$, M. Reichelt ${ }^{8}$, T. S. Rhee ${ }^{1, *}$, J. Rohwer $^{11}$, \\ K. Rosenfeld ${ }^{11}$, D. Scharffe ${ }^{1}$, H. Schlager ${ }^{13}$, U. Schumann ${ }^{13}$, F. Slemr ${ }^{1}$, D. Sprung ${ }^{6}$, P. Stock ${ }^{13}$, R. Thaler ${ }^{11}$, \\ F. Valentino ${ }^{9}$, P. van Velthoven ${ }^{14}$, A. Waibel ${ }^{15}$, A. Wandel $^{16}$, K. Waschitschek ${ }^{17, * *}$, A. Wiedensohler ${ }^{8}$, I. Xueref-Remy ${ }^{5}$,
} A. Zahn ${ }^{6}, \mathbf{U} . \operatorname{Zech}^{18}$, and H. Ziereis ${ }^{13}$

${ }^{1}$ Max-Planck-Institut für Chemie (MPI), Air Chemistry Division, Joh.-J.-Becherweg 27, 55128 Mainz, Germany

${ }^{2}$ Lufthansa Technik, Lufthansa Base, Frankfurt Airport, FRA WE 24, 60546 Frankfurt, Germany

${ }^{3}$ Institut für Umweltphysik, Universität Heidelberg, INF229, 69120 Heidelberg, Germany

${ }^{4}$ GKSS-Research Centre, Institute for Coastal Research (GKSS), Max-Planck-Str. 1, 21502 Geesthacht, Germany

${ }^{5}$ Laboratoire des Sciences du Climat et de l'Environnement (CNRS), Unité mixte CNRS/CEA, CEA Saclay Orme des

Merisiers - Bat.703, Pièce 26, 91191 Gif sur Yvette Cedex, France

${ }^{6}$ Institut für Meteorologie und Klimaforschung (IMK), Forschungszentrum Karlsruhe, Weberstr. 5, 76133 Karlsruhe, Germany

${ }^{7}$ Enviscope GmbH, Arnoldhainer Str. 5, 60489 Frankfurt, Germany

${ }^{8}$ Leibniz-Institut für Troposphärenforschung (IFT), Permoserstr. 15, 04318 Leipzig, Germany

${ }^{9}$ University Bern, Institut für Klima- und Umweltphysik, Sidlerstr. 5, 3012 Bern, Switzerland

${ }^{10}$ University of Lund, Division of Nuclear Physics, P.O. Box 118, 22100 Lund, Sweden

${ }^{11}$ Lufthansa Technik, VIP \& Government Jet Maintenance, Weg beim Jaeger 193, 22335, Hamburg, Germany

${ }^{12}$ University of East Anglia, School of Environmental Sciences, Norwich, NR4 7TJ, UK

${ }^{13}$ Deutsches Zentrum für Luft- und Raumfahrt (DLR), Institut für Physik der Atmosphäre, 82230 Wessling, Germany

${ }^{14}$ Royal Netherlands Meteorological Institute (KNMI), P.O. Box 201, NL-3730 AE, de Bilt, the Netherlands

${ }^{15}$ Lufthansa, Environmental Division, Frankfurt Airport Center, Hugo-Eckener-Ring B.649, 60549 Frankfurt, Germany

${ }^{16}$ Heggeman Aerospace AG, Zeppelinring 1-6, 33142 Büren, Germany

${ }^{17}$ Garner CAD Technik GmbH, Argelsrieder Feld 2/4, 82234 Oberpfaffenhofen, Germany

${ }^{18}$ KOLT Engineering GmbH, Argelsrieder Feld 20, 82234 Oberpfaffenhofen, Germany

*now at: Korean Polar Research Institute, Sangrokgu Sa-2-dong 1270, Ansan 426-744, Korea

** now at: RUAG Aerospace Services GmbH, P.O.Box 1253, 82231 Wessling, Germany

Received: 13 March 2007 - Published in Atmos. Chem. Phys. Discuss.: 18 April 2007

Revised: 30 July 2007 - Accepted: 18 September 2007 - Published: 27 September 2007

\begin{abstract}
An airfreight container with automated instruments for measurement of atmospheric gases and trace compounds was operated on a monthly basis onboard a Boeing 767-300 ER of LTU International Airways during longdistance flights from 1997 to 2002 (CARIBIC, Civil Aircraft for Regular Investigation of the Atmosphere Based on an Instrument Container, http://www.caribic-atmospheric.com). Subsequently a more advanced system has been developed, using a larger capacity container with additional equipment
\end{abstract}

Correspondence to: F. Slemr

(slemr@mpch-mainz.mpg.de) and an improved inlet system. CARIBIC phase \#2 was implemented on a new long-range aircraft type Airbus A340600 of the Lufthansa German Airlines (Star Alliance) in December 2004, creating a powerful flying observatory. The instrument package comprises detectors for the measurement of $\mathrm{O}_{3}$, total and gaseous $\mathrm{H}_{2} \mathrm{O}, \mathrm{NO}$ and $\mathrm{NO}_{\mathrm{y}}, \mathrm{CO}, \mathrm{CO}_{2}, \mathrm{O}_{2}$, $\mathrm{Hg}$, and number concentrations of sub-micrometer particles ( $>4 \mathrm{~nm},>12 \mathrm{~nm}$, and $>18 \mathrm{~nm}$ diameter). Furthermore, an optical particle counter (OPC) and a proton transfer mass spectrometer (PTR-MS) are incorporated. Aerosol samples are collected for analysis of elemental composition and particle morphology after flight. Air samples are taken in glass

Published by Copernicus Publications on behalf of the European Geosciences Union. 
containers for laboratory analyses of hydrocarbons, halocarbons and greenhouse gases (including isotopic composition of $\mathrm{CO}_{2}$ ) in several laboratories. Absorption tubes collect oxygenated volatile organic compounds. Three differential optical absorption spectrometers (DOAS) with their telescopes mounted in the inlet system measure atmospheric trace gases such as $\mathrm{BrO}, \mathrm{HONO}$, and $\mathrm{NO}_{2}$. A video camera mounted in the inlet provides information about clouds along the flight track. The flying observatory, its equipment and examples of measurement results are reported.

\section{Introduction}

In view of the ever more detailed questions about the myriad of coupled chemical and physical processes in the global atmosphere, while witnessing human induced disturbances of this system that affect climate within a human's lifetime, the need for advancing observational capacities is evident. Besides intensive atmospheric chemistry research largely based on national and international measurement campaigns using ship, aircraft, satellites and ground stations, there is a need for systematic approaches in observing the chemistry and composition of the atmosphere with sufficient detail. To some degree the making of "observations" is moving from the realm of science to that of technology and engineering. Our understanding of atmospheric processes, be it chemical or physical, has grown enormously, and further advancement is based on improved models and an adequate supply of sufficiently detailed, relevant data. Next to the understanding of processes, there is a clear need for monitoring to comprehend the entire system. Besides this, for systems as complex and variable as the Earth's atmosphere (not to mention its coupling with the other complex components of the planetary system, like the biosphere) the need for monitoring in terms of meteorology and chemistry, and detecting changes is evident (www.ipcc.ch).

One has indeed seen an increasing number of surface based monitoring sites (e.g., ESRL-GMD, http://www.cmdl. noaa.gov/, GAW, http://www.wmo.ch (Montzka et al., 2003; WMO, 2004)), and the detailed information we have about $\mathrm{H}_{2}, \mathrm{CH}_{4}$, halocarbons and $\mathrm{CO}_{2}$ is by virtue of this excellent work of monitoring. At several of such observatories the number of trace gases measured has been increased by installing sophisticated systems for measuring a host of trace gases in real time (the ALE/GAGE/AGAGE network http://cdiac.ornl.gov/ndps/alegage.html (Prinn et al., 2000)). Thus, next to the basic, yet powerful process of collecting air samples on a weekly to monthly basis, highly detailed high frequency information becomes available. This all enables a better understanding of trace gas sources, transport, chemistry, and mixing. Generally, observatories are on mountains or in coastal regions for the purpose of obtaining data representing air masses that are not affected by immediate input from nearby sources of air pollution. Next to these stationary and dedicated sites, platforms of opportunity such as ships are used by which the marine boundary layer can be probed (Lelieveld et al., 2004). Even the Trans-Siberian railroad with an instrumented observation wagon transported over the $9000 \mathrm{~km}$ long track from Moscow to Vladivostok and back is used (http://www.troica-environmental.com; Crutzen et al., 1998; Hurst et al., 2004).

Remote optical sensing from the surface is a powerful technique that can deliver vertical profiles or column integrated data for aerosols and certain trace gases continuously (e.g., NDSC, EARLINET, http://lidarb.dkrz.de/ earlinet/index.html). Remote sensing from satellites for tropospheric composition has been increasing strongly and its near global coverage is its major advantage.

Although the need for monitoring can be made clear with relative ease, the idea has really never thrilled science funding agencies since long-term commitments are involved. This forces us to be creative in developing affordable technologies. Atmospheric monitoring using civil aircraft is inherently a logical concept and in the mean time constitutes a valuable component in the colorful spectrum of global observation systems (see also IGACO, Integrated Global Chemistry Observations, http://www.igospartners.org/). The civil aircraft based projects offer the advantage of regular, long-distance, and long-term coverage. In particular the 10 to $12 \mathrm{~km}$ cruising altitude range which interestingly coincides with the upper troposphere/lower stratosphere region (UT/LS) at mid- to high latitudes is of high relevance. The UT/LS plays an important role in terms of radiative forcing by infrared-active species, such as water vapor, ozone, cirrus cloud particles which are strong absorbers of outgoing longwave radiation. At the same time, the complex UT/LS still is one of the less well documented and understood regions of the atmosphere. Main reasons for this gap in our knowledge are the extreme dynamical and chemical complexity of the UT/LS and of course the difficulty to regularly monitor the UT/LS at affordable cost. Although long-range aircraft spent most time cruising, vertical profiles of trace gases near airports can also be obtained.

Of course, the use of civil aircraft also involves some restrictions. As elucidated, the cruising altitude is limited, giving UT/LS information at mid-latitudes, and free troposphere information in the tropics. Furthermore, having a single home airport, such as Frankfurt as a base, only a limited albeit large region of the globe can be covered. Figure 1 shows the CARIBIC flight patterns which obviously are somewhat Eurocentric. A more global coverage can be obtained when combining such projects stationed in different continents. Since there is some spread in actual trajectories, the coverage is not limited to narrow corridors. Local peaks of aerosols and trace gases indicate that exhaust plumes of other aircraft are occasionally encountered, but most air intercepted is representative for the background air. The effects of other aircraft can be easily identified. The reason for the quite different flight routes to distant destinations is that 
some airlines can economize on fuel usage by using optimal meteorological conditions.

Using civil aircraft as a measurement platform is not a new idea. Walter Bischof in his 1970 Tellus paper already refers to the collection of air samples in flight for $\mathrm{CO}_{2}$ measurements in 1962, and the practice of using commercial airliners gained some momentum in the late sixties and seventies when $\mathrm{CO}$ and $\mathrm{O}_{3}$ distributions were determined using instruments strapped onto passenger seats analyzing air from the cabin ventilation system of commercial airliners (Seiler and Junge, 1969; Seiler and Junge, 1970; Tiefenau et al., 1973; Fabian and Pruchniewicz 1977). Note that in those days ozone was not removed from the cabin air supply. In the seventies, a dedicated inlet and measurement system for $\mathrm{CO}$, condensation nuclei, and $\mathrm{O}_{3}$ were permanently installed on five Boeing 737 aircraft within the GASP (Global Atmospheric Sampling Project) project of NASA (Falconer and Holdeman, 1976; Nastrom, 1979; Pratt and Falconer, 1979). After that, commercial airliners were not used, with the exception of an instrumented airfreight container operated by two persons onboard a Boeing 707 of Lufthansa Cargo Services (Dickerson, 1984; Connors et al., 1991).

Several projects involving civil aircraft, but using different approaches, were initiated in the 1990s. The MOZAIC project (Measurement of Ozone and Water Vapor by Airbus In-Service Aircraft) utilizes instruments permanently installed in nominally five Airbus A340-300 aircraft to provide measurements of $\mathrm{O}_{3}$ and $\mathrm{H}_{2} \mathrm{O}$ (since 1991) and of $\mathrm{CO}$ and $\mathrm{NO}_{\mathrm{y}}$ (since 2001) (e.g., Marenco et al., 1998). MOZAIC continues, but eventually will be superseded by a new approach using smaller instrument packages being developed and certified for Airbus A340 aircraft (IAGOS project, http: //www.fz-juelich.de/icg/icg-ii/iagos). In the NOXAR project (Measurements of Nitrogen Oxides and Ozone along Air Routes) a Boeing 747 of Swissair was quipped with an NO, $\mathrm{NO}_{2}$, and $\mathrm{O}_{3}$ analyzer (Brunner et al., 2001). The JAL project (Japan Airlines) was initially based on the collection of air samples in flasks using the air compressed by one of the jet engines. The samples were analyzed for greenhouse gases and in several instances even for their isotopic composition (Matsueda and Inoue, 1996). The JAL project is being extended, incorporating five aircraft for continuous $\mathrm{CO}_{2}$ monitoring, whereas two of these have air sample collection systems (deployed monthly). Finally, the CARIBIC project started regular flights in November 1997 (Brenninkmeijer et al., 1999, http://www.caribic-atmospheric.com). CARIBIC relies on an automatically operating airfreight container equipped with in-situ measuring instruments and sampling devices for more than 60 different trace gases and aerosol properties. The strategy of CARIBIC is to optimize the number of trace compounds that are detected and collected on the basis of regular flights. Thus once a month the container is installed in the aircraft and de-installed after presently 4 sequential flights.

One may ask what advantages a container system offers

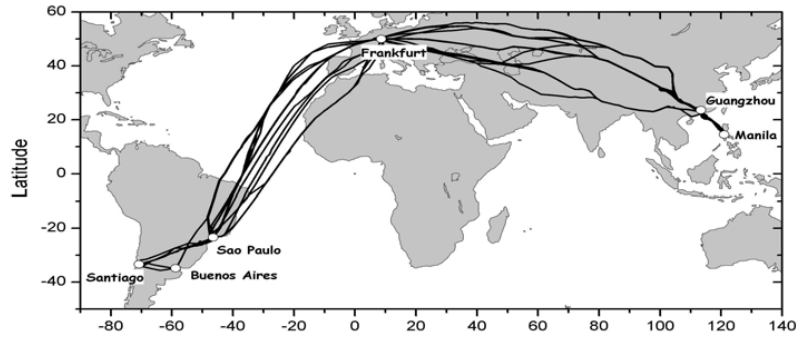

Fig. 1. Examples of flight routes to Santiago de Chile and Manila involving 4 flight legs each (brief stopovers in Rio de Janeiro and Guangzhou). The variations in the exact route and altitude mean that generally other air traffic has little if any direct influence on the intercepted air. For the flight levels of long range aircraft and typical routes, about $40 \%$ of the intercepted air is stratospheric.

and how CARIBIC can fill gaps in the current observational capacity. Foremost is that the container concept allows a wide range of equipment to be deployed. The extensive array of in situ analyzers combined with air and aerosol samplers renders CARIBIC a "flying observatory". The comprehensiveness of the payload enables studies of chemical and dynamical interactions between trace species, and the combined information facilitates the analysis of source and sink processes. The time elapsed between flights is used to analyze the air and aerosol samples while the container equipment is maintained and calibrated. The turnaround time achieved has been one month, whereas the fastest turnaround time could be one week. Frequent, highly consistent, very detailed datasets become available for several regions of the globe, which are ideally suitable for process and climatological studies. An example is the reconstruction of the annual cycles of trace gases in the tropical troposphere, the mid-latitude upper troposphere and the mid-latitude lowermost stratosphere. Moreover, CARIBIC can help to verify retrievals from satellite based remote sensing instruments (Peylin et al., 2007).

In this paper we present the new CARIBIC system comprising the inlet system, the modifications of the aircraft, and in particular the container and instrumentation. In Sect. 2 we briefly summarize the previous CARIBIC system. General considerations pertaining to the combining of the container concept with the given aircraft type and its operation, as well as the inlet system, the container and modifications to the aircraft are discussed in the following section. In Sect. 4 the current instrumentation is described in detail giving examples of measurement results for equipment new to this system.

\section{CARIBIC development}

The first CARIBIC container was deployed on a Boeing 767-300 ER of LTU International Airways that had been retrofitted with an aerosol and trace gas inlet system (Her- 


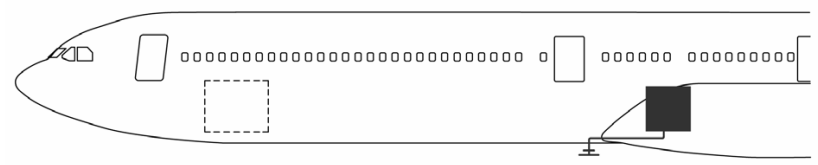

Fig. 2. Position of the CARIBIC container and the inlet system on the Airbus 340-600.

mann et al., 2001). The aircraft modifications and the instrumentation were described by Brenninkmeijer et al. (1999). Until the decommissioning of the aircraft in the course of the LTU fleet renewal in May 2002, 75 flights had been carried out mostly on the routes from Germany to the Indian Ocean and to the Caribbean. Because of the limited range of the aircraft only a limited number of flights into the southern hemisphere (in this case South Africa) could be made. The data set has so far provided a basis for studies of aerosol particle elemental composition, formation and climatology of aerosols in the tropopause region (Heintzenberg et al., 2002, 2003; Hermann et al., 2003; Martinsson et al., 2001; Papaspiropoulos et al., 2002), the interpretation of tropospheric $\mathrm{O}_{3}$ and $\mathrm{CO}$ correlations, as well as their correlation in respect to transport across the tropopause and chemical processing (Zahn et al., 2000, 2002a, 2004a and b; Zahn and Brenninkmeijer, 2003), and for process studies (Mühle et al., 2002; Zahn et al., 2002b). The data have also contributed to studies of trace gas cycles in the atmosphere (Krol et al., 2003; Sturges et al., 2000) and enabled studies of the isotopic composition of $\mathrm{CO}$ including ${ }^{14} \mathrm{CO}$ (Joeckel, 2000) as a global tracer for $\mathrm{OH}$, and of $\mathrm{H}_{2}$ and its $\mathrm{D} / \mathrm{H}$ ratio for constraining budget calculations for the atmospheric $\mathrm{H}_{2}$ budget (Rhee et al., 2006). Work on the application of $\mathrm{CO}_{2}$ concentrations and concomitant highly accurate ${ }^{13} \mathrm{C}$ and ${ }^{18} \mathrm{O}$ isotope data is in progress. Furthermore, for 360 air samples extracts of condensable gases $\left(\mathrm{CO}_{2}, \mathrm{~N}_{2} \mathrm{O}\right.$, hydrocarbons, etc.) have been archived for $\mathrm{D} / \mathrm{H},{ }^{13} \mathrm{C} /{ }^{12} \mathrm{C}$ and ${ }^{37} \mathrm{Cl} /{ }^{35} \mathrm{Cl}$ measurements of hydrocarbons and $\mathrm{CH}_{3} \mathrm{Cl}$ (Pupek et al., 2005). All in all a considerable amount of systematic and hitherto unavailable data have been obtained. Data from the CARIBIC-Boeing 767 flights are accessible on request (consult www.caribic-atmospheric.com).

\section{The new CARIBIC system}

\subsection{General considerations}

The aircraft of choice was a new Airbus A340-600 (certified in 2004), which is a long range $(14000 \mathrm{~km})$ stretched member (up to 380 passengers) of the A340 family (www.airbus. com). Lufthansa acquired 10 of these aircraft over the period May 2003-October 2004, and this fleet is expanding. The integration of the CARIBIC system in the aircraft required several modifications. Most important were the structural changes to the hull around the mounting position of the inlet system, followed by the installation of the air tubing and cables. Also needed were a container connector interface, a control panel in the cockpit, and modifications to electrical hardware and electronics and software. At all stages tests were to be conducted and the modifications were concluded with a test flight. The estimated two weeks of work on the aircraft needed would have inflicted an undesirable downtime and it was decided to use the grounding period of the aircraft used for retrofitting it with a broadband internet system (Boeing Conexxion) by Lufthansa Technik (FLYNET). The joint modifications took place November 2004.

The A340-600 differs from the previously used Boeing 767 in a for CARIBIC important aspect, namely the cargo loading door of the forward cargo bay is located towards the front of the aircraft, and not near the wings (Fig. 2). This means that the measurement container's position is towards the wing box, in the rear of the forward cargo bay above the leading edge of the belly fairing. The reason for this is that the CARIBIC container must be loaded first into the aircraft followed by the standard contingent of cargo containers and pallets. At the airport of destination the regular cargo can be unloaded, leaving the CARIBIC container in position. Upon return at the airport of origin, first the cargo is unloaded, followed by the careful de-installation and removal of the CARIBIC container. Thus, the aircraft structure implies that the container position is in the aft of the forward cargo bay.

Ideally, the air/aerosol inlet system should be positioned directly beneath the container. Short tubing minimizes contamination/loss for gases and aerosol particles. However, below the actual container position the belly fairing is present. Its shell is too thin to support an inlet system. Therefore, the actual position of the inlet system was shifted forward by about $2 \mathrm{~m}$. As a result of these aircraft structural considerations, the container is about $25 \mathrm{~m}$ away from the nose of the aircraft and the inlet system about $23 \mathrm{~m}$. From a mechanical/structural point of view the height of the inlet system should be minimal. From an analytical point of view one should sample air totally outside the aircraft's boundary layer. Data from Airbus Hamburg about the exact airflow field and pressure distribution around the aircraft were used to find a good compromise. According to their data, the boundary layer thickness at the position of the inlet is $\sim 25 \mathrm{~cm}$. The CARIBIC inlet system is, despite its more complex geometry, not an over-dimensioned probe, being comparable in size to drain masts and VHF antennas.

The scientific and analytical requirements have to be met within the constraints of the aircraft's structure, safety and operation, and hence compromises concerning the analytical capabilities have to be made. The safety requirements of civil aircraft are extensive and strict. Compounds classified as dangerous (e.g. liquid nitrogen) cannot be used in a passenger aircraft. Concerning the container and the instruments there are mechanical requirements (loads on 
equipment, racks and container as a whole during acceleration/crash conditions), electrical requirements (bonding, fuses etc), and requirements concerning combustible materials. Furthermore, specifications with respect to the control of equipment (computer controlled switching on and off of the many analyzers) and concerning the absence of conducted or radiated electromagnetic energy have to be met. For the inlet system there are strict regulations concerning its impact on the aerodynamics, on the integrity of the aircraft hull, absence of vibrations, its behavior at icing conditions, stability, etc. The responsibility for the design and construction of all modifications to the aircraft, the integration of the container, and for the certification process with the German and European Aviation Authorities were entirely with Lufthansa Technik (www.LHT.de).

The technical process of realizing CARIBIC took about two years and was completed by a test flight during which an extensive protocol of tests, including vibration measurements, was conducted.

The intention is that the new CARIBIC system will be operational over at least ten years. Airline companies operate in a most competitive commercial environment, and scientific projects (against a background of global change) can in principle be tolerated if these do not disturb routine operation and do not cause significant additional cost. Years of positive experience with CARIBIC involving 2 airlines, 2 aircraft types, and 2 containers especially concerning their installation, flying and de-installation give great confidence in the sustainability in this respect. The environment division of Lufthansa supports CARIBIC as one of several activities to better understand the atmosphere and to reduce pollution and noise. The scientific consortium of CARIBIC pays Lufthansa Cargo standard rates for the airfreight cost of the measurement container.

\subsection{The CARIBIC inlet system}

Details of the inlet system, in particular the aerosol sampling characteristics, will be published elsewhere. Here, we summarize the main aspects. The inlet has been designed around the analytical requirements a) to optimize aerosol particle sampling at cruising speeds of $\sim 250 \mathrm{~m} / \mathrm{s}, \mathrm{b}$ ) to provide dedicated air intakes for different trace gases with heating systems for inlet tips and tubing, c) to provide ram pressure thus obviating the use of pumps for some instruments, and d) to host a set of three miniature DOAS telescopes for remote sensing and a video camera for observing clouds. The inlet structure is that of a hollow spar machined out of a block of aluminum, to which the three flanges of the three separate probes are fixed. A fore- and aft-shell form the enclosure and contribute to the rigidity of the assembly, using almost 100 fasteners. Figure 3 shows the inlet system as designed for LHT by Garner CAD Technics GmbH (Oberpfaffenhofen, Germany) in close cooperation with the scientists and manufactured by Heggeman Aerospace (Büren,
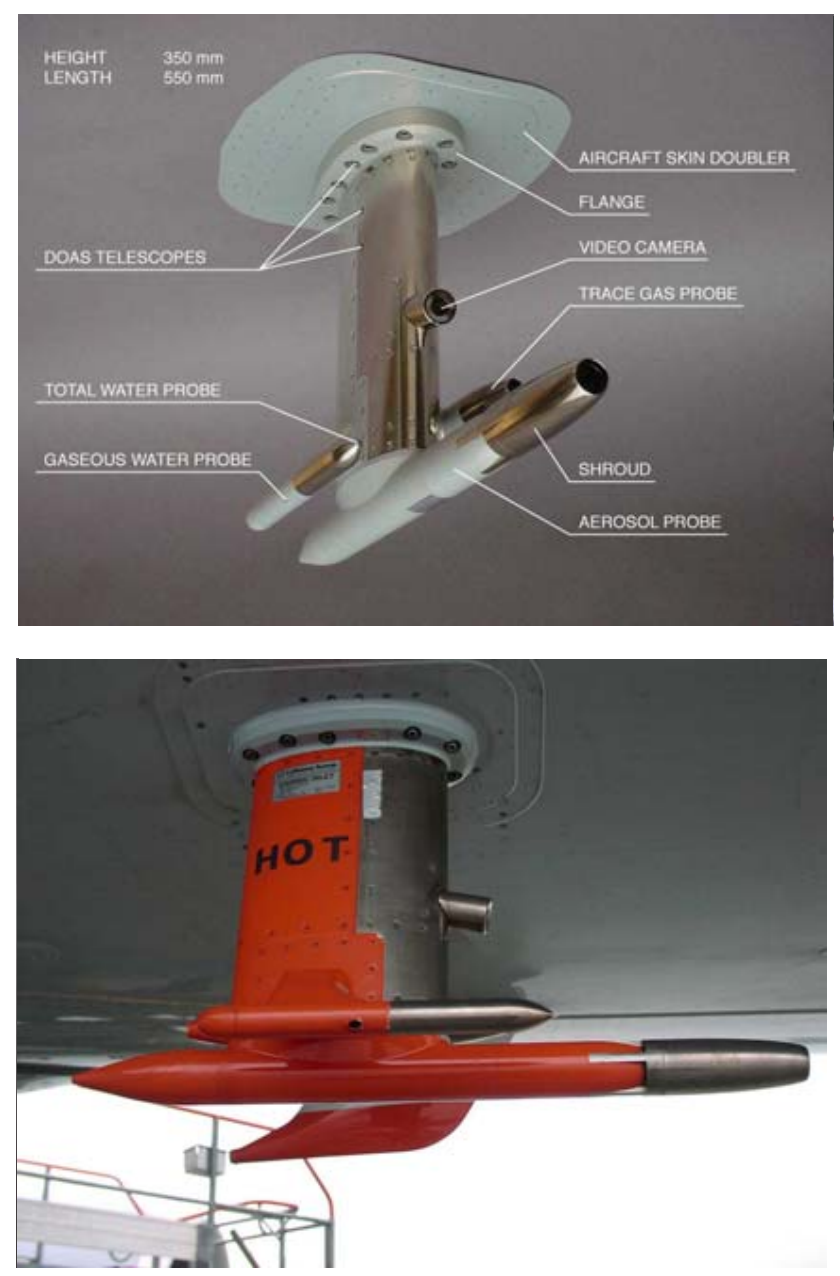

Fig. 3. Photographs of the CARIBIC inlet system. On the right hand a liquid drain mast is visible behind the inlet.

Germany). It consists of 25 structural aluminum elements and is $55 \mathrm{~cm}$ long, $34 \mathrm{~cm}$ high, $18 \mathrm{~cm}$ wide. Its mass is about $3.5 \mathrm{~kg}$. All essential parts exposed into the flight direction are nickel plated to improve hardness. The total number of components is about 60 , comprising the aluminum parts, tubing, heater elements, temperature sensors, insulation, plugs, DOAS telescope, brackets, and the video camera.

One of the main scientific design considerations was to obtain representative aerosol sampling characteristics at the cruising speed of nominally $250 \mathrm{~m} \mathrm{~s}^{-1}$. This means that the aerosol tube (diffuser tube) should sufficiently slow down the air flow from which aerosol particles are to be sampled. It also means that a shroud is applied. This shroud is a $12 \mathrm{~cm}$ long, $4 \mathrm{~cm}$ OD aerodynamic cylinder upstream of the aerosol diffuser tube itself and supported by four prongs. Most air entering the shroud passes through the four circular slits between the prongs. Because the shroud is heated, one of these $7 \times 7 \mathrm{~mm}^{2}$ square-cross-section prongs is hollow to supply a channel for feeding through temperature sensor and heater 


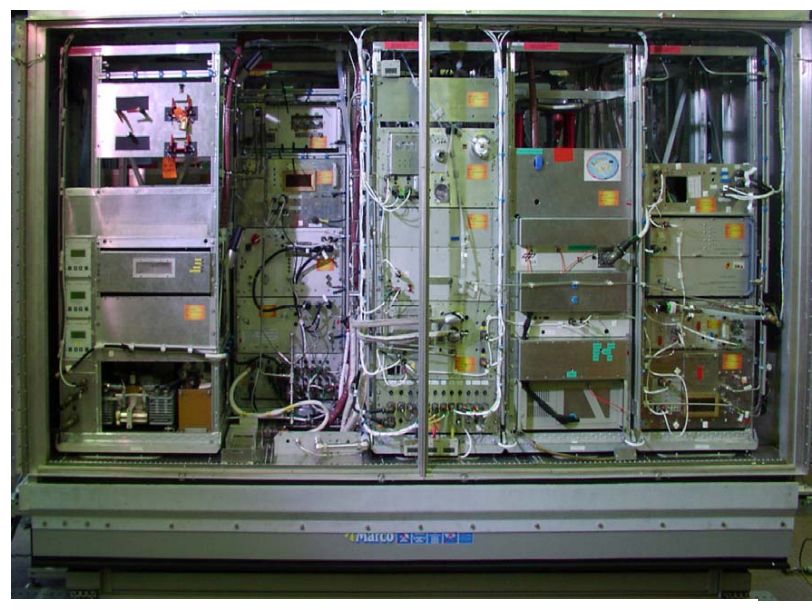

Real

\begin{tabular}{|c|c|c|c|c|}
\hline TRAC & $\begin{array}{c}\text { DOAS } \\
\text { OPC } \\
\mathrm{CPC}>4 \mathrm{~nm} \\
\mathrm{CPC}>12 \mathrm{~nm} \\
\mathrm{CPC}>18 \mathrm{~nm} \\
\text { AEROSOL } \\
\text { SAMPLER }\end{array}$ & $\begin{array}{l}\text { PUMP UNIT } \\
\text { ADSORPTION } \\
\text { TUBES }\end{array}$ & \multirow{2}{*}{$\mathrm{NO} / \mathrm{NO}_{\mathrm{y}}$} & $\begin{array}{c}\text { GAS } \\
\text { CYLINDERS }\end{array}$ \\
\hline PTR-MS & $\begin{array}{c}\text { CONTAINER } \\
\text { CONNECTOR } \\
\text { BRACKET }\end{array}$ & $\begin{array}{l}\mathrm{O}_{3} \\
\mathrm{CO} \\
\mathrm{O}_{2}\end{array}$ & & $\begin{array}{l}\mathrm{CO}_{2} \\
\mathrm{CO} \\
\mathrm{O}_{2}\end{array}$ \\
\hline
\end{tabular}

Fig. 4. Frontal photo of the container (top) and a schematic drawing of the position of individual instruments viewed from above (bottom).

wires. The aerodynamic function of the shroud is to make the aerosol sampling characteristics as little dependent on flight conditions (angle of attack) as possible (cf. e.g. Murphy and Schein, 1998). A fraction of the air flowing through the shroud enters the inlet tip of the diffuser tube with its $6.4 \mathrm{~mm}$ inlet orifice which is located centrally $8 \mathrm{~cm}$ downstream inside the shroud. Both shroud and this inlet tip are heated by heating foils to prevent icing. The diffuser itself is a four degree half-angle diffuser while the outlet orifice is $4 \mathrm{~mm}$. The actual sample air for the particles is taken downstream inside the diffuser via a centrally positioned, unheated forward pointing electro-polished 3/8" stainless steel pickup tube bent with a radius of $100 \mathrm{~mm}$. Because the sampled air is heated from ambient temperatures of -60 to $-30^{\circ} \mathrm{C}$ to container temperatures around $30^{\circ} \mathrm{C}$, all aerosol measurements in the container can be considered as "dry" measurements. Moreover, not only water will evaporate from the particles, but also semi-volatile species like ammonium nitrate or organics (An et al., 2007; Stanier et al., 2007), because the heating in the inlet system is strong $(60$ to $90 \mathrm{~K})$, the sampling lines to the aerosol instruments are relatively long (between 3.4 and $4.0 \mathrm{~m}$ ), and respective residence times are long with approximately $0.5 \mathrm{~s}$ to $0.8 \mathrm{~s}$. Unfortunately, the length of the sampling lines was determined by the aircraft structure and not by analytical reasons. This evaporation must be considered, when interpreting the results of the OPC measurements (Sect. 4.6) and the particle sample analysis (Sect. 4.7).

The water probe is mounted on the right (looking in flight direction), $1 \mathrm{~cm}$ above the aerosol probe. A forward facing (heated) inlet tip of $4 \mathrm{~mm}$ inner diameter collects air for total water measurement (gas phase plus droplets/crystals) using ram pressure to force the air through the $\mathrm{H}_{2} \mathrm{O}$ analyzers. Fluid dynamical calculations by Airbus Hamburg indicate that the air displacement by the aircraft itself causes an enhancement of cloud particles at the position of the total water inlet of 12-19\%, depending on the angle of attack. Based on the theory by Liu et al. (1989), the non-isokinetic inlet configuration causes a further cloud particle enrichment of the total water inlet of $220-500 \%$, depending on the actual aircraft speed (provided by the ARINC flight data) and the measured inlet sample flow of $50 \mathrm{vol}-1 / \mathrm{min}$. Both cloud particle enhancement factors are considered for calculating the amount of cloud water/ice. More detailed information and an estimation of the measurement uncertainty (currently estimated to $<30 \%$ ) will be given in a technical paper. A second, also heated but sideward facing inlet at near neutral pressure, like a static port, provides air for the measurement of gaseous water. The air from both intakes is transported to the instruments through electro-polished stainless steel tubing heated to $60^{\circ} \mathrm{C}$. Just before the $\mathrm{H}_{2} \mathrm{O}$ instrument, $0.6-3.1 \mathrm{vol}-1 / \mathrm{min}$ of the two sample flows of $30-50 \mathrm{vol}-1 / \mathrm{min}$ are extracted for passing through the three $\mathrm{H}_{2} \mathrm{O}$ analyzers.

The trace gas probe is located on the left, $7 \mathrm{~cm}$ above the aerosol probe. It consists of a $3 \mathrm{~cm}$ inner diameter diffuser tube with an inlet orifice of $14 \mathrm{~mm}$ diameter and outlet orifice of $12 \mathrm{~mm}$ diameter providing an effective ram pressure of about $90-170 \mathrm{hPa}$ depending on cruising altitude and speed. The inlet tip of the trace gas probe/intake is also heated to prevent icing. A small fraction of the air passing through the diffuser is withdrawn from the center flow by a $12 \mathrm{~mm}$ ID PFA lined tube perpendicular to the flow direction. This trace gas tube is heated to $40^{\circ} \mathrm{C}$. The design of the trace gas probe ensures separation of droplets as well as ice particles from the sampled air. The exhaust air from the container is vented at the rear end of the flange of the pylon close to the skin of the aircraft.

The DOAS telescopes (apertures of 1.5 degree) are mounted in a single aluminum block. Two $6 \mathrm{~mm}$ ports allow light to enter the sideward (limb) looking telescopes (10 degrees below and above the horizon), whereas a similar hole in the inlet flange feeds light into the nadir telescope. The light from the telescopes is conducted into the container to the spectrograph/detector units of the DOAS instrument by three optical cables each containing 4 individual quartz fibers. Details are given in Sect. 4.16.

A video camera (Model AVS470, Aerial View Systems, Newport Beach, CA, USA) with heated window is mounted at the leading edge of the main pylon, and allows inspection of the aerosol shroud to verify the absence of ice/rime and 
the observation of clouds during daylight flights. Between measurement flights, the inlet openings, and the DOAS ports and the camera window are sealed.

The presence of an aperture in the aircraft's skin, which is integral part of the pressurized hull system, is of special concern. To assure structural integrity and to distribute loads a doubling flange at the outer fuselage (Fig. 3) and additional frames have been used. The structural concept of the inlet itself and the concept of the inlet to airframe interface was developed by KOLT Engineering GmbH (Oberpfaffenhofen, Germany) in close cooperation with all partners followed by extensive calculations over a one year period for impacts of acceleration, vibration, fatigue and abuse loads (like bird strikes). The incorporation of supporting structural components and a proper choice of materials and treatment ensures safe long term operation.

\subsection{The CARIBIC container}

The measurement container (Fig. 4) is a modified LD-11 airfreight container $\left(3.1 \times 1.5 \times 1.6=7.44 \mathrm{~m}^{3}\right)$ with a maximum allowable gross weight of $3175 \mathrm{~kg}$. As the actual gross weight is less than half of it, more equipment can possibly be integrated, although another limiting factor is given by the available electrical power and the amount of heat that can be dissipated in the cargo bay during the flight. The cost of air freight is determined by the volume of the container, not its actual gross weight. The container is based at MPI in Mainz and is placed on a hydraulic platform. This allows the container to be lifted upwards and rolled into the institute's truck equipped with a roller system. At the airport a high-loader receives the container and lifts it into the aircraft.

The original LD-11 container, manufactured by Alcan Singen $\mathrm{GmbH}$, was modified to meet the requirements given by the accommodation of the instruments and the safety considerations. The modifications included: 1) Using $9 \mathrm{~cm}$ high stringers covered by an aluminum alloy plate, the single sheeted floor plate was turned into a stiff sandwich structure. 2) A rectangular opening was cut in the double floor to provide space for connecting the instruments to the container connector bracket incorporated in the cargo floor of the aircraft. 3) To enable access to the instruments from both sides for maintenance and calibration work, the rear wall of the container housing was replaced by three removable panels and its front opening was equipped by two large doors. The front doors and rear panels increase the mechanical stability of the container and were designed with special emphasis to reduce emission of electromagnetic radiation. 4) Altogether six aluminum racks of four different types were manufactured to carry the instruments and the auxiliary equipment. All racks are $1.36 \mathrm{~m}$ high. The three double racks and a single one behind the floor opening on the right of the Fig. 4 are 19" wide. The two racks on the left are $650 \mathrm{~mm}$ wide. To facilitate mounting and dismounting, all racks are fastened to shock mounted frames using only 4 bolts. For all racks the

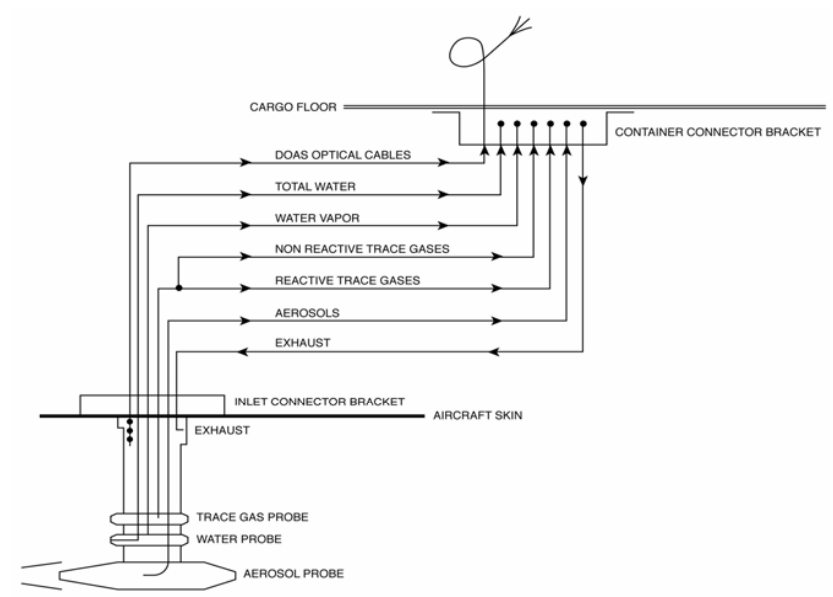

Fig. 5. Tubing connecting the inlet with the container connector bracket. The 3 optical fiber cables are continuous from the telescopes in the inlet to the spectrographs in the container.

centers of gravity were calculated and this information was used in the calculations of the compatibility with acceleration requirements of up to $9 \mathrm{~g}$ (depending on the $\mathrm{x}, \mathrm{y}, \mathrm{z}$ direction). 5) A ventilation system was incorporated. Four radial fans force air from the cargo bay into the sandwich flooring space from where it is distributed evenly around all equipment racks. Two additional radial fans withdraw air from the top right hand side (viewed in flight direction) and blow this waste air in the direction of the aircraft's cargo bay air circulation/conditioning intakes. 6) Two smoke and over-heat detectors as used in Airbus aircraft (Model SD9472-00, Apparatebau Gauting GmbH, Gauting, Germany) are mounted and are linked to a CARIBIC control panel in the cockpit.

The calculations, design and reinforcement of the container, and the construction of the racks were carried out by Enviscope GmbH in Frankfurt, Germany. The total weight of the container with the instruments is currently $1470 \mathrm{~kg}$.

\subsection{Sample air, electric and data systems}

Figure 5 shows the layout of the tubing system inside the belly of the aircraft below the cargo floor, starting at the inlet system via the inlet connector bracket mounted inside on the skin of the aircraft to the container connector bracket which is countersunk into the cargo floor. This container connector bracket contains the detachable power, signal, and air connectors. The air tubing connectors are Swagelok company's Quick-fit couplings, except for the aerosol tube which is a standard bulkhead union in order to prevent contamination of the aerosol samples by wear-off from the o-rings. There are three $3 / 8^{\prime \prime}$ O.D. electropolished stainless steel tubes. One is for aerosol particles and two supply the air for measurement of total and gaseous water. The latter ones are heated to $60^{\circ} \mathrm{C}$. The air flow from the trace gas intake is split directly above the inlet connector bracket. The air for the 


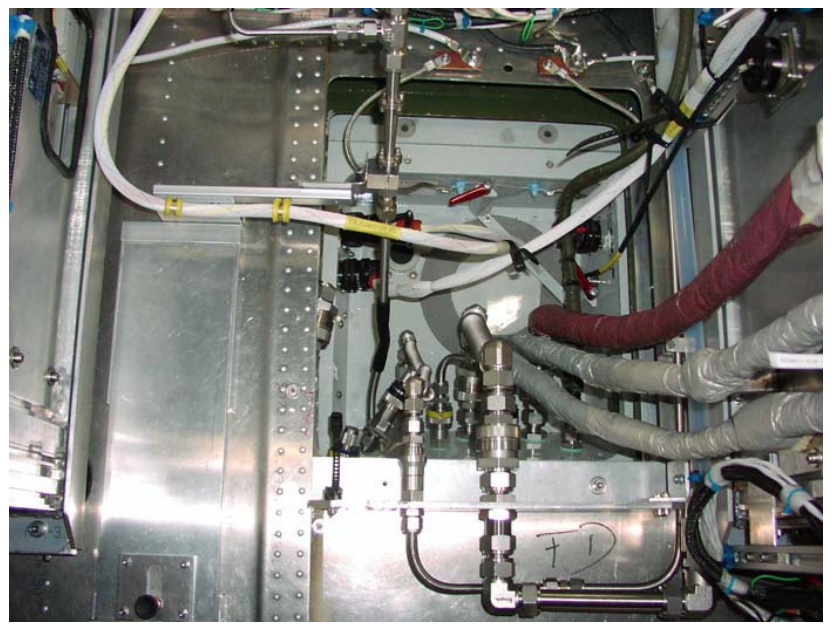

Fig. 6. Photo of the container connector bracket viewed through the cutout in the container floor. The aerosol tube is on the left (with short black flexible section). On the right the insulation of the 3 heated tubes is visible. The exhaust tube is in the centre. The non reactive trace gas tube is to its left. The 3 electrical power and data connectors are black. Also visible is the dark green sleeve of the optical fiber cables in the upper right corner. Altogether 12 connections between container and aircraft are involved plus an electrical bonding lead.

whole air sampler is drawn through an unheated 1/2" O.D. electro-polished stainless steel tube, whereas the air for most of the other trace gas instruments is led through a 3/4" O.D. aluminum tube kept at $40^{\circ} \mathrm{C}$ which is lined using a separate thin walled PFA tube. Each tube is connected on either side (inlet side, and container side) using flexible tubing. This measure is entirely because of aircraft structural considerations (avoidance of mechanical stress) and in fact is a complication from the analytical point of view. Flexible, armored PTFE tubing sections were used. For the aerosol tube we used electrically conductive PTFE (SS-NGS6-AA23X, Swagelok Companies) in order to eliminate the possibility of electrostatic charging leading to the risk of particle loss. The tube heaters are aviation quality Adel Wiggins's (Los Angeles, CA, U.S.A.) silicone rubber based ribbon heaters and their temperatures are controlled using temperature controllers and $1000 \Omega \mathrm{Pt}$ temperature sensors (Minco, Minneapolis, MN, U.S.A.). The gases (i.e. air) exhausted by the container equipment are expelled through a 3/4" stainless steel exhaust tube. The three quartz fiber cables ( $3 \mathrm{~mm}$ O.D.) from the DOAS telescopes to the analyzer are basically uninterrupted (fragile) connections from inlet to spectrographs, bundled together and protected by a flexible sheath. The control unit (power and data conversion) of the camera is permanently mounted in the aircraft near the inlet connector bracket.

Figure 6 shows a photograph of the fairly crowded container connector bracket. Three electrical connectors provide power and data from the aircraft and connect the heaters and temperature sensors in the inlet system (a 60 pin connector). One BNC connector feeds the video signal from the video camera control unit. When the container is not onboard, the quartz fiber cables are carefully coiled inside a drum (not shown in Fig. 6) placed inside the tub. Moreover, the tube openings are sealed with blind connector plugs and the container connector bracket opening is covered by a floor panel.

\section{Instrumentation}

The scientific and auxiliary equipment is powered by two power supplies that convert the aircraft 3 phase 115 VAC $(400 \mathrm{~Hz})$ into 24 and $28 \mathrm{VDC}$. The smaller of these supplies (Model EL 4kW MegaPAC, VICOR, Sunnyvale, Ca., U.S.A), called base power supply (BPS) (19", 4 height units tall $(1 \mathrm{HU}=44.45 \mathrm{~mm})$ and a mass of $22.5 \mathrm{~kg}$ ), provides $2 \mathrm{~kW}$ for the individual instrument and master (control) computers and other essential functions during the take-off and landing when the power consumption is limited. The essential functions include the heat-up and evacuation of certain instrument parts which have a relatively long spin-up time. After take-off, the second, main power supply with a capacity of $8 \mathrm{~kW}$ (manufactured by Aircraft Electronics Engineering $\mathrm{GmbH}$, Seefeld, Germany) (19", $4 \mathrm{HU}, 68 \mathrm{~kg})$ is switched on. The actual total power consumption of the fully instrumented container is $5.5 \mathrm{~kW}$ and the peak load is $7.0 \mathrm{~kW}$. For comparison, the total in-flight electrical power of an A340600 is about 4 times $80 \mathrm{~kW}$, yet electrical power usage by the container has to be kept low to minimize heat generation, to save energy, and to not affect any aircraft functions.

The power delivered by each of the power supplies is recorded by the master computer. In case of smoke and/or overheat detection, an optical and acoustical warning signal is given by the CARIBIC panel in the aircraft cockpit, and the supply of power to the container system can be switched-off by the pilot. The position and meteorological data recorded by the aircraft are provided via an ARINC bus system and stored by the master computer in the container.

The data distribution box $\left(19^{\prime \prime}, 4 \mathrm{HU}, 20 \mathrm{~kg}\right)$ forms the third interface between the container and the aircraft. It transfers signals from the smoke detectors to the aircraft, creates a relay signal indicating the presence of the container in the aircraft, transfers the ARINC aircraft data to the master computer, controls the temperature of altogether 18 heaters in the aircraft and the container (tip heaters of the inlet, tubing heaters in the pylon, the aircraft and the container), and provides the power for the camera in the pylon. The control unit of the camera is permanently installed in the aircraft.

The master computer controls all equipment and stores different types of data (ARINC, temperatures, pressures, communication with the instruments), but not measurement data. It communicates with the instruments via a custom made Ethernet network. After take-off (weight-on-wheels signal 
disappears) the main power supply is switched on and from then on the master computer activates sequentially the individual instruments to avoid power surges. In flight, the computer checks the status of the individual instruments through simple algorithms and initiates their shut down if the communication is lost. The computer also monitors the conditions inside the container, the inlet system and the sample tubing system using 4 internal pressure sensors, 2 external temperature sensors, and 18 signals from the temperature controllers in the data distribution box. The third major function of the master computer is the storing of the ARINC data. ARINC (in this case ARINC 429) is the most widespread commercial avionic data bus system. This extensive set of flight data is standard in civil aircraft and provides among others the pressure altitude, static temperature, longitude, latitude, time, and aircraft state parameters (e.g. flight angles).

Another central provision in the CARIBIC container is the gas supply unit. It was decided to have all calibration gases and supply gases stored in aluminum cylinders inside one rack that also contains the pressure regulators. The only exception is a cylinder with calibration gas used for the PTRMS which for analytical reasons has to be close to the PTRMS instrument. The supply of oxygen for the production of ozone used in the $\mathrm{NO}$ and $\mathrm{NO}_{\mathrm{y}}$ analyses is in standard aviation steel cylinders with breathing quality oxygen. These cylinders are additionally protected by concentric steel cylinders. The reason for this is to comply with the safety requirement that if in case of an engine burst, fan blades that are ejected at high speed and penetrate the fuselage and container, these cannot possibly damage the cylinders to that degree that a rapid release of oxygen would result.

Table 1 gives the overview of the instruments in the new CARIBIC container with the main specifications and lists the institutions responsible for their development and operation. Figure 7 shows schematically the tubing in the container providing air sample and collecting the exhaust gases of the instruments. Most instruments are equipped with internal pumps (not shown). The relevant aspects of the individual instruments are described below.

\subsection{Total and gaseous water}

The budget of atmospheric water vapor is of great relevance for climate and chemistry. It has recently been shown that a significant fraction of upper tropospheric air is supersaturated (up to $200 \%$ ) over ice, a feature until very recently neither captured by the ECMWF meteorological forecast model, nor by climate models. One objective of CARIBIC is to collect additional information about distributions of oversaturated regions and of the amount of water trapped in cirrus clouds

The water vapor instrument $\left(19^{\prime \prime}, 6 \mathrm{HU}, 29 \mathrm{~kg}\right)$ comprises two different detectors. A commercial chilled-mirror frost point hygrometer (CR2, Buck Research, Boulder, USA) measures humidity using the well established (absolute)

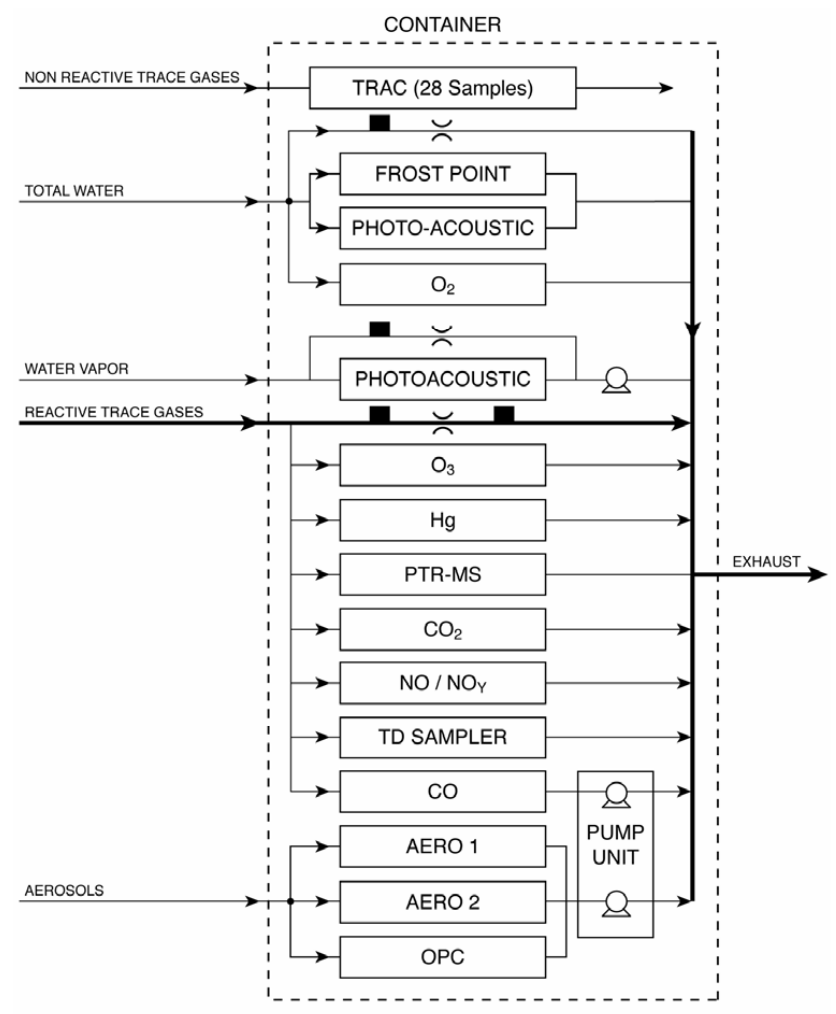

Fig. 7. Air distribution system inside the CARIBIC container. The black squares indicate pressure sensing locations. The water vapor measurements do require a suction system as there is no ram pressure on this port. The flow through the ozone sensors is not assisted by a pump. The mercury, $\mathrm{CO}_{2}$ and $\mathrm{O}_{2}$ analysers depend on pumps for pressurizing the air. For the remaining analysers where no pumping is shown, the air sample flow is maintained by suction provided by pumps in the respective units.

method. Next to this, a two-channel photo-acoustic (PA) laser-spectrometer developed at the Department of Optics and Quantum Electronics at the University Szeged in Hungary (Bozóki et al., 1999 and 2003; Szakáll et al., 2001) measures the water vapor content in a relative mode using the laser light to excite water molecules and measuring their thermal relaxation. This technique is much faster than the frost point hygrometer.

The Buck CR2 frost point hygrometer and one of the PA channels are supplied with air from the forward facing (total water) inlet. This orifice collects air having the gaseous water component plus that represented by solid and liquid phase. These phases are enriched (Sect. 3.2). The air flow through the $3 / 8^{\prime \prime}$ OD $(7.55 \mathrm{~mm}$ ID) SS electro-polished inlet tube (heated to $60^{\circ} \mathrm{C}$, overall length $2.6 \mathrm{~m}$ ) is forced by the ram pressure of $60-100 \mathrm{hPa}$. An orifice upstream of the water vapor instrument restricts the air flow to $\sim 50$ vol$1 / \mathrm{min}$, by which $\sim 75 \%$ of the ram pressure is maintained. The air is discharged through the outlet tubing connected to the exhaust in the pylon. Only a small sampling flow of 
Table 1. Instrumentation of the CARIBIC container onboard of the long-range Airbus A340-600 of Lufthansa.

\begin{tabular}{|c|c|c|c|c|}
\hline Species & $\begin{array}{l}\text { In-situ } \\
\text { or Laboratory }\end{array}$ & Principle & $\begin{array}{l}\text { Time } \\
\text { Resolution }\end{array}$ & Institute \\
\hline $\mathrm{O}_{3}$ & In-situ & $\begin{array}{l}\text { UV absorption } \\
\text { Chemiluminescence }\end{array}$ & $\begin{array}{l}8 \mathrm{~s} \\
0.2 \mathrm{~s}\end{array}$ & IMK \\
\hline $\mathrm{CO}$ & In-situ & $\begin{array}{l}\text { VUV fluorescence } \\
\text { CPC }>4 \mathrm{~nm}\end{array}$ & $\begin{array}{l}5 \mathrm{~s} \\
2 \mathrm{~s}\end{array}$ & MPI \\
\hline Aerosol concentration & In-situ & $\begin{array}{l}\mathrm{CPC}>12 \mathrm{~nm} \\
\mathrm{CPC}>18 \mathrm{~nm}\end{array}$ & $2 \mathrm{~s}$ & IFT \\
\hline $\mathrm{H}_{2} \mathrm{O}$ total & In-situ & Laser photoacoustic & $10-90 \mathrm{~s}$ & IMK \\
\hline $\mathrm{H}_{2} \mathrm{O}$ gaseous & In-situ & $\begin{array}{l}\text { Dew point } \\
\text { Laser photoacoustic }\end{array}$ & $\begin{array}{l}10-90 \mathrm{~s} \\
10-90 \mathrm{~s}\end{array}$ & IMK \\
\hline NO & In-situ & Chemiluminescence & $10 \mathrm{~s}$ & DLR \\
\hline $\mathrm{NO}_{\mathrm{y}}$ & In-situ & $\begin{array}{l}\text { Chemiluminescence } \\
\text { with } \mathrm{Au} \text { converter }\end{array}$ & $10 \mathrm{~s}$ & DLR \\
\hline $\mathrm{CO}_{2}$ & In-situ & NDIR & $15 \mathrm{~s}$ & LSCE \\
\hline $\begin{array}{l}\mathrm{O}_{2} \text { with high } \\
\text { resolution }\end{array}$ & In-situ & $\begin{array}{l}\text { Electrochemical } \\
\text { cells }\end{array}$ & $15 \mathrm{~s}$ & $\begin{array}{l}\text { University of } \\
\text { Bern }\end{array}$ \\
\hline OVOCs & In-situ & PTR-MS & $20-60 s$ & IMK \\
\hline $\begin{array}{l}\text { Halogen oxides, } \\
\mathrm{NO}_{2}, \mathrm{O}_{3}\end{array}$ & Remote & DOAS & $30 \mathrm{~s}$ & $\begin{array}{l}\text { University of } \\
\text { Heidelberg }\end{array}$ \\
\hline $\mathrm{Hg}$ & In-situ & $\begin{array}{l}\text { Enrichment and } \\
\text { atomic fluorescence }\end{array}$ & $10 \min$ & GKSS \\
\hline $\begin{array}{l}\text { Aerosol size distribution } \\
150-5000 \mathrm{~nm}\end{array}$ & In-situ & $\begin{array}{l}\text { Optical particle } \\
\text { counter }\end{array}$ & $20 s$ & IFT \\
\hline Clouds & In-situ & Video camera & $0.5 \mathrm{~s}$ & IFT \\
\hline $\begin{array}{l}\text { Aerosol elemental } \\
\text { analysis }\end{array}$ & Laboratory & $\begin{array}{l}\text { Impactor, PIXE, PESA } \\
\text { analysis }\end{array}$ & 16 samples & $\begin{array}{l}\text { University of } \\
\text { Lund }\end{array}$ \\
\hline Particle morphology & Laboratory & $\begin{array}{l}\text { Impactor, electron } \\
\text { microscope }\end{array}$ & 16 samples & $\begin{array}{l}\text { University } \\
\text { of Lund }\end{array}$ \\
\hline $\mathrm{CO}_{2}, \mathrm{CH}_{4}, \mathrm{~N}_{2} \mathrm{O}, \mathrm{SF}_{6}$ & Laboratory & $\begin{array}{l}\text { Glass canisters, } \\
\text { GC-FID-ECD }\end{array}$ & 28 samples & MPI \\
\hline NMHCs & Laboratory & $\begin{array}{l}\text { Glass canisters, } \\
\text { GC-FID }\end{array}$ & 28 samples & MPI \\
\hline VOCs & Laboratory & Adsorption, GC-MS & 16 samples & MPI \\
\hline Halocarbons & Laboratory & $\begin{array}{l}\text { Glass canisters, } \\
\text { GC-MS }\end{array}$ & 28 samples & $\begin{array}{l}\text { University of } \\
\text { East Anglia }\end{array}$ \\
\hline
\end{tabular}

$3.1 \mathrm{Vol}-1 / \mathrm{min}$ (driven by the remaining $45-75 \mathrm{hPa}$ pressure difference across the flow restrictor) is branched-off from the main airflow. The split that feeds the air to be analyzed is a 1/4" OD (4.37 mm ID) SS electro-polished sampling line (heated to $60^{\circ} \mathrm{C}$ ), connected directly upstream of the flow restrictor. The Buck CR2 frost point hygrometer receives a sample flow of $2.5 \mathrm{vol}-1 / \mathrm{min}$ with the balance of $0.6 \mathrm{vol}-1 / \mathrm{min}$ being passed through the respective total water PA channel.

The second PA channel is connected to the sideward facing inlet via an identical $3 / 8^{\prime \prime}$ OD SS inlet tube kept at $60^{\circ} \mathrm{C}$. As this inlet opening is slightly below ambient pressure, a membrane pump is used to assist the same air flow of 40 $60 \mathrm{vol}-1 / \mathrm{min}$ by suction. Also in this case a sampling flow of $0.6 \mathrm{vol}-1 / \mathrm{min}$ is branched-off and fed into the second PA channel.
Laboratory based comparisons with a high-precision chilled mirror frost point hygrometer (MBW 373-LX, MBW Calibration Ltd., Wettingen, Switzerland) give a precision and total uncertainty of the Buck CR 2 hygrometer of $\sim 0.5 \mathrm{~K}$. The precision of the two PA spectrometers currently is $\sim 0.5 \mu \mathrm{mol} \mathrm{mol}^{-1}$ at ambient pressures. The time resolution is 30-300 s for the Buck frost point hygrometer and 5-10 s for the PA sensors, depending on absolute humidity and pressure. The performance in flight is determined by the instrument characteristics, airflows, and by the inlet system, including the heated tubing. An example of the possibilities offered by the $\mathrm{H}_{2} \mathrm{O}$ instruments is given in Fig. 8, highlighting the detection of cirrus clouds. The actual sensitivity of the photo-acoustic channel (which may vary by a few percent within an hour) is inferred by correlating the data with 
those of the chilled mirror hygrometer data during post flight data processing.

\subsection{Ozone}

Ozone is the most essential component in airborne atmospheric chemistry research. In the UT/LS it plays a role in the IR radiation budget and is an important transport tracer for instance to define a chemical tropopause (Zahn and Brenninkmeijer, 2003).

For ozone we also apply 2 detection techniques, namely an accurate, precise dual-beam UV-photometer and a very fast solid-state chemiluminescence detector. The ozone instrument $\left(19^{\prime \prime}, 6 \mathrm{HU}, 29 \mathrm{~kg}\right)$ takes its sample air from the trace gas probe of the inlet system, using the "reactive trace gases" (PFA-coated) tubing to the container (Fig. 7).

The custom made dual-beam uv-photometer measures the light absorption of $\mathrm{O}_{3}$ in the UV (Hartley band). Light from a low-pressure mercury discharge lamp emitting mainly at $253.7 \mathrm{~nm}(>90 \%)$ is directed via a beam splitter through two $38 \mathrm{~cm}$ long optical cells. One cell contains the ambient air, the other one ambient air scrubbed of $\mathrm{O}_{3}$. Major parts of the optics are adapted from the commercial instrument M49 of Thermo Fisher Scientific. The sample flow of $\sim 3$ vol$1 \mathrm{~min}^{-1}$ is maintained by the ram pressure of the trace gas inlet obviating the need of a pumping system. The electronics for amplifying and processing the signal as measured by a CsTe photocathode (Hamamatsu, R1228) was newly developed. Using extremely low-noise amplifiers and an integrating 24 bit A/D converter, it measures the light intensity with a frequency of $122 \mathrm{~Hz}$, in contrast to the common sampling rate of typically $0.1 \mathrm{~Hz}$. This high-frequency measurement allows for a partial elimination of photon flux fluctuations that are characteristic for mercury discharge lamps. Comparisons with an extremely stable (but slow) laboratory standard (UMEG-NIST with $2.7 \mathrm{~m}$ absorption length which agrees with the NIST standard SRP \#15 within $<0.5 \%$ ) shows differences below $0.5 \mathrm{nmol} \mathrm{mol}^{-1}$ over the studied measurement range of $2-400 \mathrm{nmol} \mathrm{mol}^{-1}$. The $1-\sigma$ precision is currently $0.3 \mathrm{nmol} \mathrm{mol}^{-1}$ at $1 \mathrm{bar}$ at a measurement response time of $4 \mathrm{~s}$ and an accuracy of $\sim 1 \%$. This is a factor of $2-$ 3 faster and more accurate compared to similar instruments. Like other UV-photometers, it constitutes in principle an absolute measurement device, i.e., the $\mathrm{O}_{3}$ mixing ratios is calculated solely by using known physical properties $\left(\mathrm{O}_{3}\right.$ crosssection, optical path length etc.) and a ratio of measured voltages. Therefore, a calibration is not required and the instrument can be viewed as a (flying) $\mathrm{O}_{3}$ standard for the fast chemi-luminescence detector described below. Nevertheless, the instrument is cross-checked regularly with the UMEGNIST standard. Interferences with water vapor are extremely small mainly due to the newly designed heated $\mathrm{O}_{3}$ scrubber that is still able to remove as much as $800 \mathrm{nmol} \mathrm{mol}^{-1}$ ozone yet has a very small surface for water adsorption. Thus measurement artifacts due to fast changes of water vapor concen-
CARIBIC flight LH-154

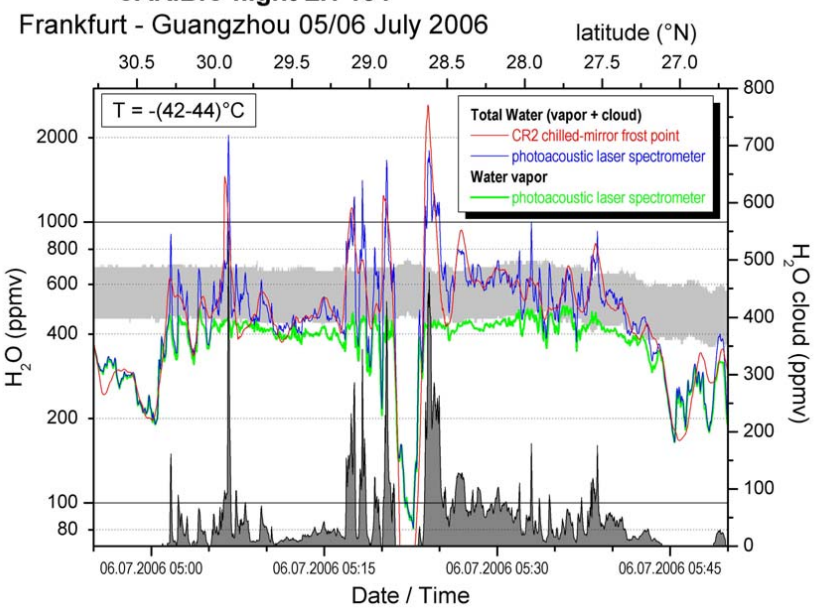

Fig. 8. The potential of both measuring gaseous water and total water using fast detector illustrated by the detection of cirrus clouds over China at $\sim 11.4 \mathrm{~km}$ pressure altitude. The grey band is the range between $100 \%$ saturation relative to ice and water. The photoacoustic signal (green) for water vapor reaches saturation versus ice at 05:02 UTC-05:20 UTC and 05:23 UTC-05:42 UTC. The photoacoustic signal for total water (blue, vapor plus ice crystals) exceeds the vapor signal during these two periods, although otherwise agreement is close (the difference of total and gaseous water signals is shown as a grey signal at the bottom). This indicates that 2 fields of cirrus clouds were intercepted. The photoacoustic measurements are fast ( $<5 \mathrm{~s}$ response time), while the chilled mirror hygrometer (red) shows "overshooting" (e.g. at 05:22 UTC) which is typical for this instrument type.

trations (Wilson and Birks, 2006), e.g. during cloud crossings, are minimized. An example of the $\mathrm{O}_{3}$ data from the UV-photometer is shown in the flight-overview of Fig. 9.

The fast $\mathrm{O}_{3}$ sensor is based on the chemiluminescence of $\mathrm{O}_{3}$ on the surface of an organic dye adsorbed on silica gel powder deposited on a $1 \mathrm{~cm}$ diameter aluminum disk (Güsten et al., 1992). The measurement frequency is $10 \mathrm{~Hz}$, which, at the cruising speed of $\sim 250 \mathrm{~m} / \mathrm{s}$, result in a high spatial resolution of merely $\sim 25 \mathrm{~m}$. However, turbulence within the inlet tube causes mixing of air which degrades the spatial resolution to effectively $30-40 \mathrm{~m}$ distance, still ample for our purposes. The fast $\mathrm{O}_{3}$ sensor is linear but needs calibration because of its variable sensitivity. The UV photometer measurements are used during the post-flight data processing for defining the fast sensor's scale. The sensor disc is typically used for $\sim 5$ flight sequences (20 flights) during which its sensitivity gradually decreases to $\sim 1 / 3$ of its initial value.

\subsection{Carbon monoxide}

Carbon monoxide (CO), together with methane, constitutes the major global atmospheric burden of reduced gases, and as such affects the oxidative self-cleansing process of the troposphere. It is a major pollutant (energy generation, transport, 


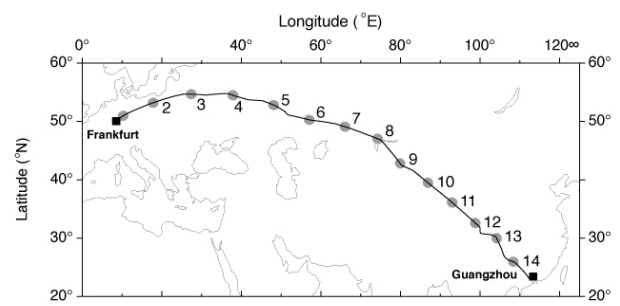

Flight \#166 Frankfurt to Guangzhou, October 19, 2006

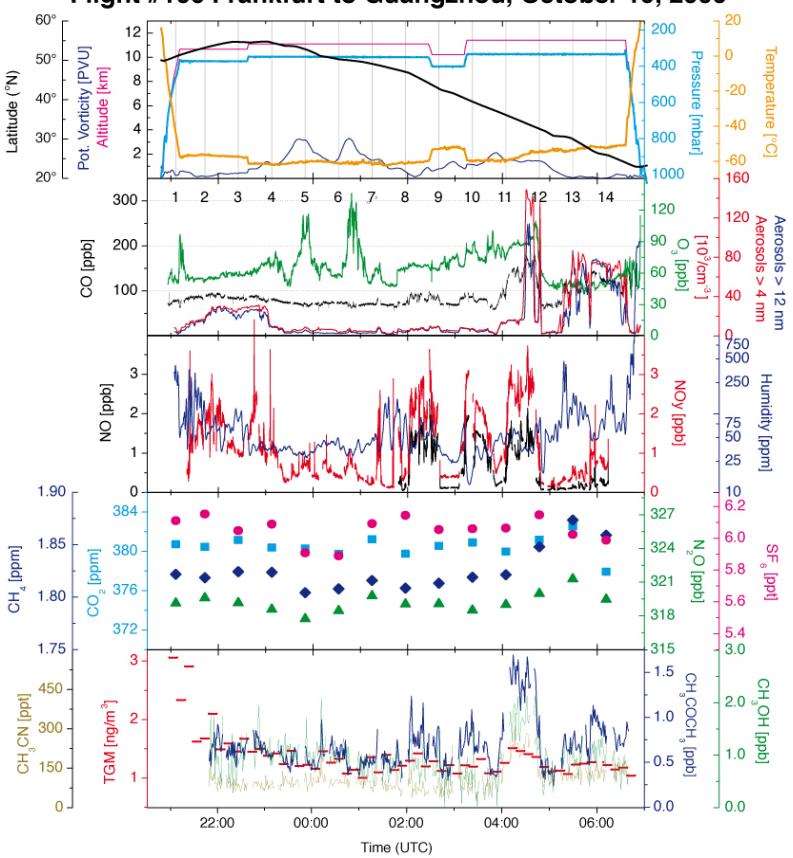

Fig. 9. Overview of the data from flight \# 166 (Frankfurt to Guangzhou). The route and the locations of whole air sampling are shown on the map. Flight altitude, latitude, and some meteorological parameters are given in the uppermost field. The two fields below it show $\mathrm{O}_{3}, \mathrm{CO}$, particle densities, $\mathrm{NO}, \mathrm{NO}_{\mathrm{y}}$, and humidity data. The following field depicts the results of analyses of whole air samples for $\mathrm{CH}_{4}, \mathrm{CO}_{2}, \mathrm{~N}_{2} \mathrm{O}$ and $\mathrm{SF}_{6}$. Data on acetone, acetonitrile, methanol, and total gaseous mercury (TGM) are shown in the lowermost field. We refer to the KNMI website (http: //www.knmi.nl/samenw/campaign_support/CARIBIC/\#LH) for detailed meteorological information.

and biomass burning) and is produced in situ in the oxidative chains of methane and other hydrocarbons. $\mathrm{CO}$ levels decline significantly crossing into the LS, whereas in the UT the frequent large scale pollution plumes carry large amounts. $\mathrm{CO}$ and $\mathrm{O}_{3}$ are often studied together, with $\mathrm{CO}$ being an indicator for pollution and a precursor molecule for $\mathrm{O}_{3}$ formation. The challenge of carbon monoxide measurements in CARIBIC is to have fast, precise data with an internationally accepted calibration.

Gas chromatography with a mercury oxide based reducing gas detector, as used in CARIBIC \#1 has been the standard measurement technique for decades. The serious disadvan- tages are the limited spatial resolution (GC technique) and the non-linearity of the detector. Therefore, a vacuum ultraviolet (VUV) fluorescence instrument (Volz and Kley, 1985; Gerbig et al., 1996 and 1999) has been incorporated instead. Here, $\mathrm{CO}$ molecules are excited by VUV radiation in an optical cell at a pressure of $\sim 10 \mathrm{hPa}$. The VUV radiation is generated by a RF generated discharge in a cell flushed with a $\mathrm{CO}_{2}$-Ar mixture, while the fluorescence is measured using a photomultiplier. Because oxygen strongly absorbs in the VUV range used, the region between the light source, detector and photomultiplier is flushed with nitrogen.

The CO analyzer (19", $4 \mathrm{HU}, 21 \mathrm{~kg})$ is based on a commercial instrument (Model AL 5002, Aero-Laser, GarmischPartenkirchen, Germany) which was retro-fitted with valves for automatic calibration and communication board for remote control by the master computer. Flow controllers have been added to stabilize the flow of nitrogen used to purge the fluorimeter in order to achieve a more stable detector signal, and the $\mathrm{CO}_{2}$-Ar gas mixture for the RF discharge lamp. A larger pump (MD4 Vario, Vacuubrand) has been used to keep sample air flow at $90 \mathrm{ml} \mathrm{min}^{-1}$ at standard conditions (STP, i.e. $273.2 \mathrm{~K}, 1013.2 \mathrm{hPa}$ ). The housing has been modified to ensure that electromagnetic interference through conduction and radiation (e.g., for the discharge lamp) is absent. To achieve a stable calibration, the tubing from the gas cylinder to the instrument is being flushed three times with a calibration gas before each flight.

Zero and span of the instrument are determined in flight every $25 \mathrm{~min}$. For this purpose zero air is generated by passing air through a cartridge filled with a $\mathrm{CO}$ oxidizing catalyst (Sofnocat, Foulger and Simmonds, 1993) via a 3-way solenoid valve which subsequently feeds a calibration gas mixture into the instrument. The mixing ratios are then calculated using the average of zero and span signals bracketing the measurement interval. During a $10 \mathrm{~h}$ flight from Frankfurt to Guangzhou the zero and the calibration signals for $250 \mathrm{nmol} \mathrm{mol}^{-1}$ are typically $2864 \pm 43 \mathrm{cps}$ and $18077 \pm 110 \mathrm{cps}$, respectively. The uncertainty estimated from the propagation of the uncertainties of calibration gas and the standard deviations of the measurement, zero, and calibration signals is typically $1.9 \%$ or $1 \mathrm{nmol} \mathrm{mol}^{-1}$, whichever is greater. Time resolution determined by the response to switching of the 3-way valve between zero and calibration gas was $5 \mathrm{~s}$ for $90 \%$ of the signal change.

The advantages of the VUV technique are excellent linearity, reproducibility, and fast response. Over the period of 2 years its sensitivity declines by $\sim 50 \%$ which can be restored by cleaning the optical cell. Tests on air cylinders show agreement with other laboratories within fractions of a nmol mol-1 over a range of 50 to $300 \mathrm{nmol} \mathrm{mol}^{-1}$. Results are calculated relative to the NOAA/ESRL standards based on as comparisons at the GAW quality assurance center at EMPA, Dübendorf, Switzerland. An example of the CO measurements is presented in the flight-overview of Fig. 9. 


\subsection{Nitrogen oxides}

$\mathrm{NO}$ is one of the main catalysts in tropospheric photochemistry. Produced by soils, lightning and combustion processes it reacts readily with ozone, resulting in $\mathrm{NO}_{2}$ and $\mathrm{O}_{2}$. During the daytime, $\mathrm{NO}_{2}$ is photolysed, releasing an oxygen atom that reforms ozone. The important catalytic role is clear in reactions such as $\mathrm{HO}_{2}+\mathrm{NO}$, which yields $\mathrm{OH}$ and $\mathrm{NO}_{2}$. NO recycles radicals and maintains the oxidative cycle. In CARIBIC we measure $\mathrm{NO}$ and $\mathrm{NO}_{\mathrm{y}}$ (the sum of all reactive nitrogen species: $\mathrm{NO}, \mathrm{NO}_{2}, \mathrm{HNO}_{3}, \mathrm{PAN}, 2 \mathrm{~N}_{2} \mathrm{O}_{5}, \mathrm{HNO}_{2}$, $\mathrm{HNO}_{4}$, and nitrates), with the future option of also detecting $\mathrm{NO}_{2}$. In the stratosphere total reactive nitrogen $\left(\mathrm{NO}_{\mathrm{y}}\right)$ consists mainly of $\mathrm{HNO}_{3}$. In the troposphere the $\mathrm{NO}, \mathrm{NO}_{2}$, $\mathrm{HNO}_{3}$ and PAN are the main components of total reactive nitrogen. Systematic data for nitrogen oxides in the UT/LS region are rare which underscores the importance of this payload in CARIBIC.

The technique applied for the measurement of $\mathrm{NO}$ and $\mathrm{NO}_{\mathrm{y}}$ is similar to the one used on the DLR Falcon 20 research aircraft for several years (Ziereis et al., 2000). It is based on detecting the light emission from the reaction of $\mathrm{NO}$ with $\mathrm{O}_{3}$ using a photomultiplier. The sum of reactive nitrogen compounds $\left(\mathrm{NO}_{y}\right)$ is measured by a catalytic conversion technique in which all $\mathrm{NO}_{\mathrm{y}}$ species are reduced to $\mathrm{NO}$ in a gold tube maintained at $300^{\circ} \mathrm{C}$ using a reducing gas added to the sample air flow. Two NO detectors allow the concomitant measurement of $\mathrm{NO}$ and $\mathrm{NO}_{\mathrm{y}}$. The commonly used $\mathrm{CO}$ reducing gas in the converter is not allowed on civil aircraft because of its toxicity. Therefore, hydrogen from a small metal hydride storage system (storage capacity $2 \mathrm{~g} \mathrm{H}_{2}$ ) is used here. The conversion efficiencies for typical $\mathrm{NO}_{\mathrm{y}}$ and non- $\mathrm{NO}_{\mathrm{y}}$ compounds using $\mathrm{H}_{2}$ instead of $\mathrm{CO}$ were determined in the laboratory and found mostly to agree with those found by Volz et al. (2005). The conversion efficiency for $\mathrm{NO}_{2}$ and $\mathrm{HNO}_{3}$ with $\mathrm{H}_{2}$ was the same as with $\mathrm{CO}$. Opposite to the quantitative conversion of $\mathrm{HCN}$ reported by $\mathrm{Volz}$ et al. (2005) we found only 6-9\% conversion efficiency. The resulting $\mathrm{HCN}$ interference is then correspondingly smaller than the one stated by Volz et al. (2005) and amounts 6$27 \mathrm{pmol} \mathrm{mol}^{-1}$ at typical HCN background concentrations of 100-300 $\mathrm{pmol} \mathrm{mol}^{-1}$.

The NO+NO ${ }_{y}$ system constitutes one complete rack $\left(19^{\prime \prime}\right.$, $24 \mathrm{HU}, 171 \mathrm{~kg}$ ) stretching from the front to the back of the container. The chemiluminescence detectors are operated at a sample flow of $1.51 \mathrm{~min}^{-1}$ (STP) extracted from the PFA lined trace gas sampling line. To avoid the loss of nitric acid, a major compound of $\mathrm{NO}_{\mathrm{y}}$, PFA sampling lines heated to $40^{\circ} \mathrm{C}$ are used also inside the analyzer systems (Neuman et al., 1999). For obtaining an optimal signal to noise ratio, the photomultipliers are cooled by a closed cycle refrigerator to about $-30^{\circ} \mathrm{C}$. To suppress the influence of air sample humidity on the sensitivity of the instrument, the oxygen/ozone stream is humidified. With this precaution, no sensitivity change during a flight has been observed so far.
Sensitivity checks of the two NO detectors are carried out before and after each flight using a standard concentration of $\mathrm{NO}$ in $\mathrm{N}_{2}$. The $\mathrm{NO}$ standard is diluted into the $\mathrm{NO}$ free zero air by means of a mass flow controller. The sensitivities of the two NO channels are about 15 counts s${ }^{-1} \mathrm{~mol} \mathrm{pmol}^{-1}$. The background signal is determined every $10 \mathrm{~min}$ for a period of about $1 \mathrm{~min}$ and is typically $1000-2000 \mathrm{cps}$. The conversion efficiency of the gold converter is checked before and after each flight by adding known amounts of $\mathrm{NO}_{2}$ produced by gas phase reaction of $\mathrm{NO}$ with $\mathrm{O}_{3}$. Zero air artifacts are determined before and after each flight, and also in flight every $2 \mathrm{~h}$ by addition of synthetic air from a gas cylinder. The detection limit of the $\mathrm{NO}$ and $\mathrm{NO}_{\mathrm{y}}$ system for $10 \mathrm{~s}$ data is about 1 to $2 \mathrm{pmol} \mathrm{mol}^{-1}(2 \sigma)$. The estimated accuracy for the $\mathrm{NO}$ and $\mathrm{NO}_{\mathrm{y}}$ measurements is $8 \%$ for an ambient $\mathrm{NO}$ level of $50 \mathrm{pmol} \mathrm{mol}^{-1}$ and $7 \%$ for an ambient $\mathrm{NO}_{\mathrm{y}}$ level of $450 \mathrm{pmol} \mathrm{mol}^{-1}$. During the POLINAT-2 (Pollution from Aircraft Emissions in the North Atlantic Flight Corridor) and EXPORT 2000 (European Export of Particulates and Ozone by Long-Range Transport) campaigns $\mathrm{NO}$ and $\mathrm{NO}_{\mathrm{y}}$ measurements on board the Falcon 20 made by DLR were compared to similar measurements on board other aircraft during flight. The instruments on the different aircraft showed good agreement (Ziereis et al., 1999; Brough et al., 2003). An example of the $\mathrm{NO}$ and $\mathrm{NO}_{\mathrm{y}}$ data is given in the flight overview, Fig. 9.

\subsection{Aerosol particles - condensation particle counters}

Aerosol particles are emitted directly by a wide range of natural and man-made processes. As they are also formed in situ by gas-to-particle conversion, their physical and chemical properties vary strongly. Also their number distribution is highly variable mainly due to their short atmospheric residence time in the order of hours to weeks. Aerosol particles affect the Earth's radiation budget directly through light scattering and absorption but also indirectly (cloud processes), clearly having a significant - yet ill quantified - impact on climate (www.ipcc.ch). In view of the relatively modest information we have about UT/LS particles, this aspect of CARIBIC has some priority.

The CARIBIC container houses three units with aerosol instruments, which are supplied with air via electro-polished stainless steel tubing from the aerosol inlet. These units are located as close to the container connector bracket as possible to minimize loss of particles in tubing. The low pressure needed to maintain the flow through the systems using critical orifices is provided by a diaphragm pump (MD4C, Vacuubrand) in the pump unit of the container $\left(19^{\prime \prime}, 8 \mathrm{HU}, 55 \mathrm{~kg}\right)$. In the units named AERO 1 (19", $6 \mathrm{HU}, 30 \mathrm{~kg})$ and AERO 2 $\left(19^{\prime \prime}, 5 \mathrm{HU}, 42 \mathrm{~kg}\right)$ altogether three modified condensation particle counters (CPCs, TSI Model 7610, TSI Inc., St. Paul, MN, USA) are installed. AERO 2 also contains the particle sampler unit described in Sect. 4.7. CPCs measure the integral particle number concentration of all particles larger than 


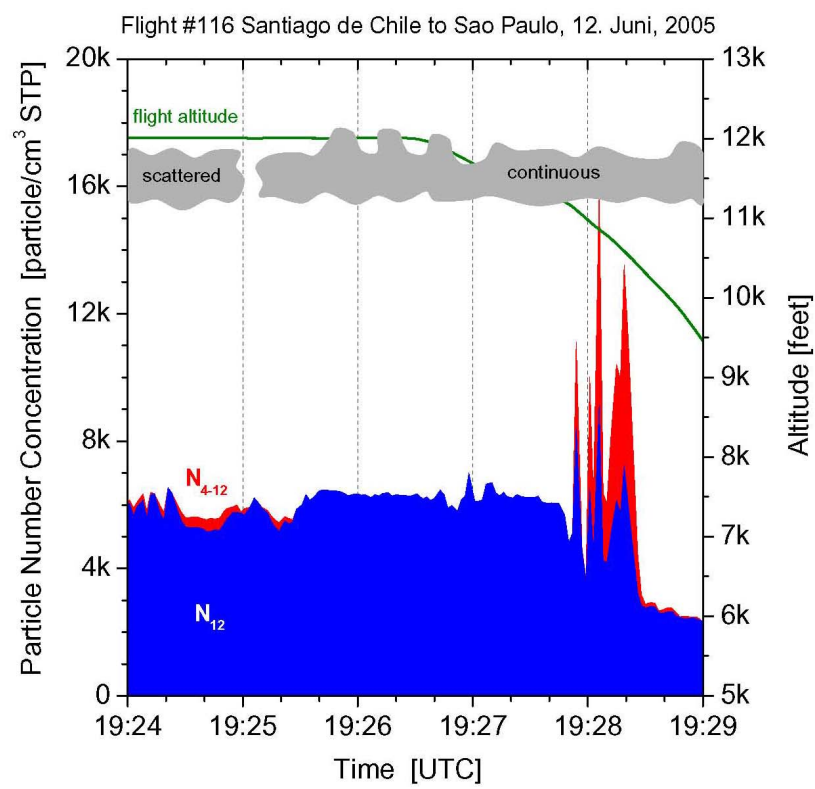

Fig. 10. The occurrence of ultrafine particles (between 4 and $12 \mathrm{~nm}$ ) was recorded just after descending through clouds (but not inside the clouds) while approaching São Paulo Airport. The use of the video camera allows to investigate if cloud droplets or ice particles impinge on the leading edge of the shroud or the aerosol diffuser tube do enhance particle counts significantly or not, and hence, if there are measurements artifacts. In this case, there seem to be no artifacts. The origin of the ultrafine particles observed below the cloud is a question still to be answered.

a certain threshold diameter. Inside these CPCs, the sample air is first saturated with butanol vapor and cooled subsequently in order to grow the particles by condensation of this working fluid. The enlarged particles are finally detected by scattering of light from a laser diode. Extensive laboratory tests at operating pressures of $160-1000 \mathrm{hPa}$ were made to ensure the proper function of the instruments at cruise altitudes, and to obtain pressure-dependent counting efficiency curves (Hermann and Wiedensohler, 2001). Experimental uncertainties for Aitken mode and ultrafine particle number concentrations amount to $\pm 10 \%$ and $\pm 35 \%$, respectively (Hermann et al., 2003).

To measure concentrations in different particle size ranges, the lower threshold diameters of two CPCs were shifted to a smaller and a larger diameter, respectively, by changing the temperature difference between the saturator and the condenser block. The new temperature differences are $11^{\circ} \mathrm{C}$ and $26^{\circ} \mathrm{C}$ (compared to $17^{\circ} \mathrm{C}$ in the original version) and additional temperature sensors were used to monitor the temperatures of the saturator and the condenser block in each CPC. Consequently, the three CPCs now have lower threshold diameters (50\% maximum counting efficiency) of 4, 12, and $18 \mathrm{~nm}$, respectively, at $200 \mathrm{hPa}$ operating pressure (Hermann and Wiedensohler, 2001). The upper threshold diameter of particles detected by the CPCs is estimated to about $2 \mu \mathrm{m}$ and is rather determined by particle losses inside the CPCs than by the particle sampling efficiency of the CARIBIC inlet system. However, as in the UT the Aitken mode particles normally dominate the total particle number concentration (as it can be seen by comparing the CPC and OPC data), the exact upper threshold diameter is not important for the CARIBIC CPC measurements.

The time resolution of the CPCs was set by the control software to $2 \mathrm{~s}$, corresponding to a spatial resolution of about $0.5 \mathrm{~km}$. During data processing, measured number concentrations are corrected for particle losses in the inlet (estimated using the known inlet sampling efficiency of the old CARIBIC inlet and the CFD modeling flow field results) and in the sampling line (calculated using equations from the literature). Therefore, the size dependent correction factors were averaged over the respective CPC particle size window, considering only particle diameters smaller than $150 \mathrm{~nm}$ for the same reason as given above. Correction factors for $\mathrm{CPC}$ counting efficiencies, for coincidence in the CPC optics, and for pressure-dependent $\mathrm{CPC}$ flow rates were taken from Hermann and Wiedensohler (2001). These volume flow rates, which are determined by critical orifices in the CPCs, range from 1.1 to 1.6 liter/min (volume) and have been calibrated in the laboratory for operating pressures between 60 and $1000 \mathrm{hPa}$.

Results of the CARIBIC CPC measurements onboard the old CARIBIC system (Boeing 767, LTU) have already been presented in several publications (e.g. Hermann et al., 2003). Figure 10 shows a first example of the new measurements. Particle concentrations were combined with the video recordings (Sect. 4.14) to reveal the exact location of a high particle concentration event. The mechanism leading to the high number concentration of ultrafine particles observed just below the cloud (believed to be a real effect) is not known. Likewise, the question of droplet break-up and other artifacts, caused by the inlet while measuring in clouds (Murphy et al., 2004), which can be addressed by using the video camera, is still under investigation.

\subsection{Aerosol particles - optical particle counter}

The third aerosol rack unit $\left(19^{\prime \prime}, 7 \mathrm{HU}, 26 \mathrm{~kg}\right)$ houses an Optical Particle Counter (OPC, PCASP-X, Passive Cavity Aerosol Spectrometer Probe, PMS, Boulder, CO, USA). OPCs operate on the principle that the light scattered by individual particles within a laser cavity is a direct function of their size, assuming spherically shaped particles. Each particle produces a pulse of radiant energy during its transit through the laser beam, which is detected by two photo diodes. As the OPC is intended to measure the aerosol particle size distribution in the size range of $0.15-10.0 \mu \mathrm{m}$ (accumulation and coarse particle mode), about six orders of magnitude in signal intensity have to be covered. Hence, in the CARIBIC OPC, two diodes are used with different 
sensitivities. The loss of particles in the CARIBIC inlet system, however, limits the maximum diameter of detected particles to approximately $5 \mu \mathrm{m}$. This value is estimated based on the experience with the previous CARIBIC inlet and will have to be determined more accurately by either wind tunnel or CFD modeling studies in the future.

For CARIBIC, the original instrument was considerably modified (Reichelt, 2007). New photodiodes and new signal processing electronics were installed. The new analog-todigital converter allows the binning of particles into 256 size channels instead of 32 in the original instrument. The majority of these channels are located in the sub-micrometer size range, but even there, because of the low accumulation mode number concentrations in the UT, channels have to be combined for most of the time in order to improve the counting statistics. This can be different during aircraft descents. The sheath $(0.5-1.0 \mathrm{liter} / \mathrm{min})$ and sampling flow rates $(0.05-0.2$ liter $/ \mathrm{min})$ through the OPC are controlled by two mass flow controllers. In order to maintain a constant volume flow rate, the sampling line pressure and temperature are controlled. As for the first two aerosol units, this flow is maintained by the pump unit in the container. The time resolution of the OPC is software controlled and was set to $20 \mathrm{~s}$. However, again, because of the low concentration of accumulation and coarse mode particles normally encountered in the UT/LS and hence statistical reasons, the time resolution is only on the order of minutes in practice.

The OPC has been operating less regularly than foreseen because of a variety of mechanical and electronic problems. Nevertheless, some excellent results have been obtained (cf. Fig. 11 and Sect. 4.7 below).

\subsection{Aerosol particle sampling and analysis}

Aerosol particle collection proved very valuable during the first phase of CARIBIC (Martinsson et al., 2001; Papaspiropoulos et al., 2002; Martinsson et al., 2005). Presently a new multi-channel impactor sampler (Nguyen et al., 2006) collects particle samples for quantitative elemental analysis by Particle-Induced X-ray Emission (PIXE) (Papaspiropoulos et al., 1999) and Particle Elastic Scattering Analyses (PESA) (Nguyen and Martinsson, 2007). The minimum detection limits of, e.g. carbon, nitrogen, oxygen, sulfur and iron for $1.5 \mathrm{~h}$ sampling are $4,1,2,2$ and $0.1 \mathrm{ng} / \mathrm{m}^{3}$ (STP). The inaccuracy of the elemental analyses is estimated to be within 10\% (Papaspiropoulos et al., 2002). In addition, material is collected separately for analysis of single particles with transmission and scanning electron microscopy (TEM, EELS and EFTEM). Particles are collected by impaction on ultra thin, clean plastic foils housed in a sampler block (16 $\times 16 \times 46 \mathrm{~cm}^{3}$ ) inside the AERO 2 unit. This block contains 14 channels operated by solenoid valves for sequentially collecting samples $(\sim 1.5 \mathrm{~h}$ time resolution) and two channels sampling the whole flight $(\sim 8-10 \mathrm{~h})$. Each sequential channel collects simultaneously one sample for PIXE/PESA anal-

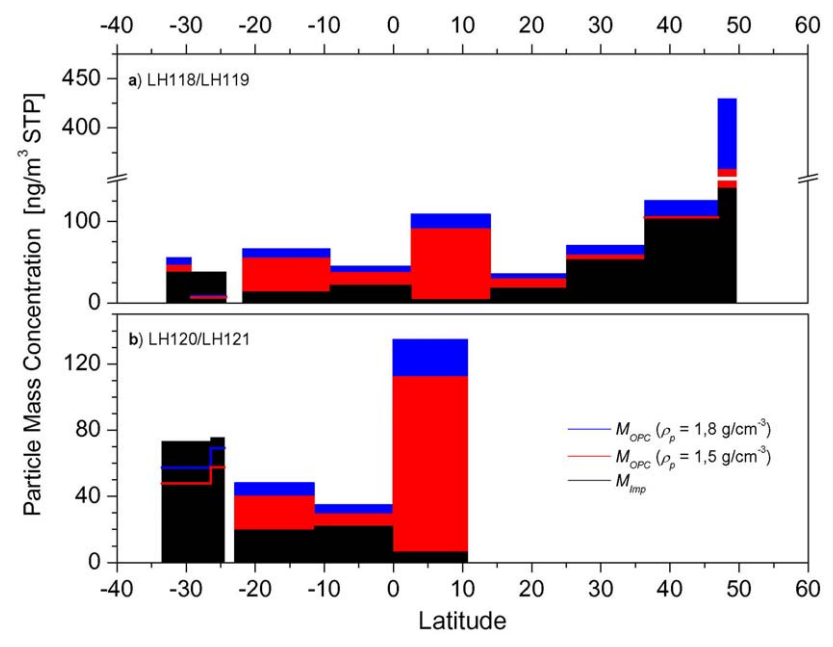

Fig. 11. Aerosol mass as calculated for the OPC measurements assuming spherical particles compared with aerosol mass inferred from the PIXE analyses assuming the aerosol mass is sulfate. These measurements were made during cross Atlantic flights (http://www. knmi.nl/samenw/campaign_support/CARIBIC/\#LH). Considering the vastly different techniques used, the agreement at mid latitudes is encouraging. In the equatorial region, the OPC data indicate substantially higher aerosol masses. A plausible explanation is that this missing mass is carbon, which is not detected by PIXE but can be detected using PESA in Lund.

ysis and two smaller samples for single particle analysis. A cyclone separator up-stream of the sampler restricts the upper particle size entering the sampler to $2 \mu \mathrm{m}$ diameter. Calibration with respect to the penetration at $360 \mathrm{hPa}$ pressure revealed a $100 \%$ penetration efficiency for sub-micrometer particles and a 50\% cut-off of $2 \mu \mathrm{m}$ equivalent aerodynamic diameter (Nguyen et al., 2006). Calibration with $1002 \mathrm{hPa}$ inlet pressure at the sampler revealed a lower cut-off diameter (50\% level) of the impactors of $0.08 \mu \mathrm{m}$. During operation in the UT/LS the reduced pressure will result in an even smaller cut-off diameter. The collection efficiency of particles larger than $0.2 \mu \mathrm{m}$ equivalent aerodynamic diameter (above cut-off size region) was determined to be $97 \%$ (Nguyen et al., 2006).

Figure 11 shows the comparison between elemental analyses and the OPC results. This comparison is based on the assumption that the aerosol consists of spherical particles composed of sulfuric acid. Both these assumptions are naturally oversimplifications of the actual conditions. Quantitative analysis with PESA shows that the carbonaceous fraction of the UT/LS aerosol is important (Ngyuen and Martinsson, 2007). Electron microscopic studies further show that the majority of the particles are non-spherical, often highly structured and present evidence of two or more phases of material. Still reasonable agreement is found for many of the sampling periods. Particularly during the passage of ITCZ, large differences appeared between the two methods used to estimate the particle mass concentration. Meteorological 
analysis indicates passage through deep, convective, precipitating clouds for both ITCZ samples. The low concentration of sulfur can be expected from the perspective of the incorporation of water-soluble aerosol in clouds (Martinsson et al., 2000; Schwarzenböck et al., 2000), thus pointing to other possible aerosol components constituting the major fractions of the aerosol, such as carbonaceous aerosol. This first glimpse of the comparison between the elemental mass concentration measurements and the OPC-derived estimate of the mass concentration in Fig. 11 will be followed up in a future paper reporting compositional and size distribution features in detail.

\subsection{Carbon dioxide}

Understanding and quantifying the fluxes of the main greenhouse gas $\mathrm{CO}_{2}$ on the global scale is a gargantuan task. CARIBIC can contribute accurate data for the UT/LS region for which the present global dataset is very sparse. In flight, the gas also is an important tracer for understanding the composition air masses intercepted as to their origin, like biomass burning, contact with the biosphere during day and night, etc.

The $\mathrm{CO}_{2}$ analyzer (CONDOR-C, 19", $6 \mathrm{HU}, 37 \mathrm{~kg}$ ) uses the common non-dispersive infrared absorption (a LICOR 6252, LI-COR Biosciences, Lincoln, NE 68504, USA). The detection is performed at $4.26 \mu \mathrm{m}$ in a differential mode. The accuracy and the reproducibility are enhanced by using in flight calibration with a set of 3 gases, and by controlling the pressure and flow rate in the optical cells. The spectrometer temperature is kept at $40^{\circ} \mathrm{C}$ through the combination of a heating element and a fan that produces rapid circulation. The pressure of the sample and the reference cells are regulated at $1080 \mathrm{hPa}$ with an accuracy $<0.1 \mathrm{hPa}$ by using two absolute quartz pressure sensors (Druck RPT 200). The flow rate at standard pressure and temperature (STP) of the sample air and the reference gas are also controlled during flight respectively at $600 \mathrm{~cm}^{3} \mathrm{~min}^{-1}$ and $70 \mathrm{~cm}^{3} \mathrm{~min}^{-1}$ (volume). All process controls are performed under Real Time Linux on a PC104 CPU.

To exclude interference of water with the $\mathrm{CO}_{2}$ measurement, the sampled air is dried using a bundle of Nafion membrane tubes. The instrument is calibrated using two calibration gases every $30 \mathrm{~min}$. The set of calibration gases in high pressure cylinders is calibrated before and after the flight at LSCE in Paris following the calibration protocol of the CARBOEUROPE project. The precision of CONDOR was determined to be better than $0.5 \mu \mathrm{mol} \mathrm{mol}^{-1}$. Operation in CARIBIC has proven to be less routine as projected with the performance gradually improving.

\subsection{Oxygen with ultra high precision}

Variations in the $\mathrm{O}_{2} / \mathrm{N}_{2}$ ratio in air not only mirror those in $\mathrm{CO}_{2}$, but provide additional essential information about the complex interaction between the atmosphere, oceans, and biosphere. To obtain useful information, variations in the $\mathrm{O}_{2}$ content of air have to be measured with about the same absolute precision as that for $\mathrm{CO}_{2}$. This means that the relative precision has to be 1000 times better than that for $\mathrm{CO}_{2}$ measurements. Bearing in mind that it took the " $\mathrm{CO}_{2}$ community" decades to achieve traceable accurate precise measurements, this obviously is a considerable analytical challenge. As the $\mathrm{O}_{2} / \mathrm{N}_{2}$ ratio measured in an air flow is prone to variability and biases introduced by fractionation in the inlet systems, the incorporation of equipment to measure the $\mathrm{O}_{2} / \mathrm{N}_{2}$ ratio in CARIBIC is of experimental nature.

The optimal analytical detection for aircraft applications is electrochemical. Electrochemical cells provide typically $20 \mathrm{mV}$ for $20 \%$ of $\mathrm{O}_{2}$ proportional to its partial pressure. Such cells are robust, small and cheap. Several cells are used simultaneously. The essence of the $\mathrm{O}_{2}$ system is to obtain an extremely high degree of control over temperature, pressure and flux of the air in the electrochemical cells. Moreover, the electronic processing of the weak electrical signal demands a range of measures to enable a sufficient signal to noise ratio at ambient $\mathrm{O}_{2}$ concentrations of approximately $21 \%$ with a resolution of $0.0001 \% \mathrm{O}_{2}$ to match the $\mathrm{CO}_{2}$ resolution.

A unit $\left(19^{\prime \prime}, 6 \mathrm{HU}, 39 \mathrm{~kg}\right)$ contains the electrochemical cells, temperature/flow/ pressure control, computer and also an additional $\mathrm{CO}_{2}$ analyzer intended to help troubleshooting (e.g. fractionation effects). The low noise amplifier unit gives a noise/signal ratio in the order of 1 part per million. The short term stability of the $\mathrm{O}_{2}$ cell requires frequent switching between sample and standard gases which cancels much of this variability. The oxygen measurement precision is still slightly too low but improves gradually (Valentino et al., $2007^{1}$ ).

\subsection{Mercury}

Measuring mercury is of scientific interest because its biogeochemical cycle is not well understood. Moreover, its toxicity, its enrichment in the aquatic food chain and its accumulation in the cryosphere are a cause of concern. There exist relatively few mercury measurements, in particular in the UT/LS, and the global dataset to study transport pathways can be significantly increased by CARIBIC measurements.

Because of the exceedingly low concentrations at which $\mathrm{Hg}$ species exist in the background atmosphere, measurement techniques incorporate a pre-concentration step (amalgamation with precious metals, preferably gold). In the remote atmosphere the total gaseous mercury (TGM) fraction consists of gaseous elemental mercury (GEM), the dominant compound by far, and the operationally defined reactive gaseous mercury (RGM) present in much lower concentrations. Beside GEM and RGM, other volatile organic

\footnotetext{
${ }^{1}$ Valentino, F. L., Leuenberger, M., Nyfeler, P., Moret, H.-P., Sturm, P., Slemr, F., and Brenninkmeijer, C. A. M.: Development of a continuous $\mathrm{O}_{2}$ and $\mathrm{CO}_{2}$ analyzer for automated operation on a passenger aircraft, Environ. Sci. Technol., submitted, 2007.
} 
mercury species, such as dimethyl mercury and monomethyl mercurychloride also interact with gold absorbers. They are desorbed as elemental mercury and thus detected by atomic absorption and fluorescence detectors (Slemr et al., 1979).

The CARIBIC instrument is based on automated dual channel, single amalgamation, cold vapor atomic fluorescence analyzer (Tekran-Analyzer Model 2537 A, Tekran Inc., Toronto, Canada) which measures gaseous mercury at background concentrations. The instrument consists of one rack unit $\left(19^{\prime \prime}, 7 \mathrm{HU}, 36 \mathrm{~kg}\right)$. The instrument features two gold cartridges. While one is adsorbing mercury during a sampling period, the other is being thermally desorbed using argon carrier gas stream and $\mathrm{Hg}$ is detected using cold vapor atomic fluorescence spectroscopy (CVAFS). The functions of the cartridges are then reversed, allowing continuous sampling of the incoming air stream. A $45 \mathrm{~mm}$ diameter Teflon pre-filter (pore size $0.2 \mu \mathrm{m}$ ) protects the sampling cartridges against contamination by particulate matter. To reduce the number of gas cylinders in the container, the instrument is operated with the $0.25 \% \mathrm{CO}_{2}$ in argon gas mixture used for operation of the $\mathrm{CO}$ instrument. As the addition of $\mathrm{CO}_{2}$ to argon reduces the sensitivity of the fluorescence detector by $35 \%$, the sampling interval had been initially set to $15 \mathrm{~min}$ ( $\sim 225 \mathrm{~km}$ flying distance) with an air sample flow rate at STP of $0.51 \mathrm{~min}^{-1}$, and has been reduced to $10 \mathrm{~min}$ since April 2006. An adsorber is being developed to remove $\mathrm{CO}_{2}$ from the gas mixture to further reduce the sampling interval to merely $5 \mathrm{~min}$.

The compression of sample air from the trace gas inlet using the PFA coated tubing into the dual gold cartridge assembly $(500 \mathrm{hPa})$ was achieved by an additional pump inside the unit. This membrane pump has been extensively tested for not contaminating the system with $\mathrm{Hg}$. Since the response factor of the Tekran instrument is pressure dependent (Ebinghaus and Slemr, 2000) a pressure monitoring module is placed at the sample vent. This allows for an empirical pressure correction algorithm normally applied to airborne operations with large altitude changes. A detection limit $\sim 0.1 \mathrm{ng}, \mathrm{Hg} \mathrm{m}^{-3}$ and a reproducibility of about $0.05 \mathrm{ng} \mathrm{Hg} \mathrm{m}^{-3}$ is achieved. The instrument is calibrated after every other flight by repeated injection of known amounts of mercury. The sampling system of the CARIBIC instrument and the conditions in the UT/LS (low humidity) are similar to those encountered in the Antarctic, for which Temme et al. (2003) found that RGM will be measured in addition to elemental mercury and organomercury compounds. The CARIBIC measurement will thus represent total gaseous mercury (TGM).

An example of the TGM data is shown in the flight overview in Fig. 9. Results of mercury measurements in biomass burning plumes have been published recently and we refer to this work for additional information (Ebinghaus et al., 2007).
4.11 Oxygenated volatile organics by proton-transferreaction mass-spectrometry (PTRMS)

Oxygenated volatile organic compounds (OVOCs) are omnipresent in the atmosphere. They are produced in the chain processes of hydrocarbon oxidation and are emitted from combustion and burning. In the upper troposphere they may substantially contribute to the formation of radicals (Singh et al., 1995, 2004). Up to now only a rather limited number of measurements of OVOCs are available in the UT/LS, exclusively gathered during research aircraft campaigns.

The problem of measuring OVOCs has been addressed by the development of PTRMS by Lindinger and his colleagues (1998). Its applicability for airborne deployment was demonstrated by Hansel et al. (1999) and de Gouw et al. (2004). The adaptation and automated operation of a PTRMS system has formed a major challenge for CARIBIC. PTRMS applies a soft ionization for trace gases that have a greater proton affinity than water $(166.5 \mathrm{~kJ} / \mathrm{mol})$. This allows specific ionization and thus the separation of these trace gases from the air matrix molecules. $\mathrm{H}_{3} \mathrm{O}^{+}$ions are generated in a hollow cathode discharge in water vapor. The proton transfer reaction takes place in a drift tube at $\sim 2.8 \mathrm{hPa}$.

A PTRMS system (Ionicon, Innsbruck, Austria) was modified for automated on-line measurement of selected OVOCs, specifically acetone, methanol, acetaldehyde and acetonitrile. The unit is integrated in a wide rack $\left(26^{\prime \prime}, 22 \mathrm{HU}\right.$, $123 \mathrm{~kg}$ ). Improvements were necessary to detect the low concentrations generally occurring in the UT/LS, to automate its operation, to make it compact, and to fulfill the aviation safety requirements. The major modifications are: a) the power supply changed to 24 and $28 \mathrm{~V} \mathrm{DC}$, b) the integration of effective filters to suppress electromagnetic interference, $c$ ) a reduction of power consumption, instrument size and weight, d) the installation of a third turbo-molecular pump enabling an increase in the number of primary ions and to operate the PTRMS at higher drift tube pressure, e) the integration of a more powerful (and much smaller) highvoltage supply for the drift tube, f) the implementation of shock mounts for the most sensitive parts, g) the incorporation of a cylinder with calibration gas (Apel/Riemer, USA) for online calibration during flight and of a zero air filter (Ptcatalyst, $\left.350^{\circ} \mathrm{C}\right)$ for the determination of the background signal, h) the addition of temperature control (to $\sim 35^{\circ} \mathrm{C}$ ) of all tubes (made of PFA) that are in contact with the analyzed air, i) the implementation of a 3/8"OD PFA bypass line that flushes the inlet line with $\sim 201 \mathrm{~min}^{-1}$ (controlled by a flow controller), and $\mathrm{j}$ ) a design and an implementation of new measurement and control software (based on LabView).

The PTRMS is calibrated once an hour. First, sample gas is passed through the zero-air generator ( $\mathrm{Pt}$ catalyst) and is measured for 3 min to determine the background mass spectra. Second, two calibrations (each $3 \mathrm{~min}$ ) are conducted by adding small amounts of calibration gas to the main sampling line which leads to additional signals corresponding to $\sim 1$ 
and $\sim 2 \mathrm{nmol} \mathrm{mol}^{-1}$. These two calibrations are used to determine the sensitivity of the instrument. The standard deviation of the sensitivity is typically $7-12 \%$ during a $12 \mathrm{~h}$ flight. A $500 \mathrm{nmol} \mathrm{mol}^{-1}$ calibration gas containing acetone, acetonitrile, acetaldehyde, and methanol (among others) with a stated uncertainty of 5\% is used (Apel/Riemer) and found to be stable within a period of 2 years. Consequently, the typical total uncertainty of the CARIBIC PTRMS measurements is about $15 \%$. The detection limits with $5 \mathrm{~s}$ resolution are 6,25 , 40 , and $125 \mathrm{pmol} \mathrm{mol}^{-1}$ for acetonitrile, acetone, acetaldehyde, and methanol, respectively. The precision given by the count rate statistics for a concentration of $500 \mathrm{pmol} \mathrm{mol}^{-1}$ is $7 \%, 8 \%, 8 \%$, and $9 \%$, respectively for typical sensitivities of $27,22,22$, and $17 \mathrm{cps} \mathrm{mol} \mathrm{nmol}^{-1}$. After change of the instrument parameters (acceleration voltages, pressure), the known interference of ozone with acetaldehyde measurements (mainly in stratospheric air) disappeared. An example of the PTRMS measurements is shown in the flight overview of Fig. 9, giving results for acetonitrile $\left(\mathrm{CH}_{3} \mathrm{CN}\right)$, acetone $\mathrm{CH}_{3} \mathrm{C}(\mathrm{O}) \mathrm{CH}_{3}$, and methanol $\left(\mathrm{CH}_{3} \mathrm{OH}\right)$. Levels of $\mathrm{CH}_{3} \mathrm{CN}$ are generally fairly constant (lifetime $\sim 1$ year), yet it is a good indicator for biomass burning. Acetone - an important carbonyl component - shows many interesting features related to its direct emissions and omnipresence in the troposphere, and chemical reactivity. Methanol is one of the most abundant OVOC in the atmosphere.

\subsection{Air sampling}

Collecting air samples is a simple but powerful approach. Long-lived gases, particularly $\mathrm{CO}_{2}, \mathrm{CH}_{4}, \mathrm{~N}_{2} \mathrm{O}, \mathrm{SF}_{6}$, can be measured in the laboratory with required high precision and accuracy, as well as a host of other gases that cannot be analysed rapidly during the flight, such as halocarbons and hydrocarbons. When one includes isotope measurements like ${ }^{2} \mathrm{H}$ in $\mathrm{H}_{2},{ }^{13} \mathrm{C}$ and ${ }^{18} \mathrm{O}$ in $\mathrm{CO}_{2},{ }^{13} \mathrm{C},{ }^{17} \mathrm{O}$, and ${ }^{18} \mathrm{O}$ in $\mathrm{CO},{ }^{2} \mathrm{H}$ and ${ }^{13} \mathrm{C}$ in $\mathrm{CH}_{4},{ }^{2} \mathrm{H}$ and ${ }^{13} \mathrm{C}$ in several hydrocarbons, and for instance ${ }^{37} \mathrm{Cl}$ in $\mathrm{CH}_{3} \mathrm{Cl}$, most extensive information about a sampled air parcel is obtained. Limitation of air sampling is that the trace gases of interest must be sufficiently stable in the air container and that that discontinuous information is obtained.

The whole air sampler TRAC (triggered retrospective air collector) consists of a pumping unit and two sample canister units (together 19", $24 \mathrm{HU}, 137 \mathrm{~kg}$ ) all under control of a separate computer unit, which also controls the absorber unit $\left(19^{\prime \prime}, 3 \mathrm{HU}, 7 \mathrm{~kg}\right.$, see Sect. 4.13). The TRAC is designed to collect sufficient amount of air (about 10 liter STP) within a short time (minute) in order to resolve smaller scale features, e.g. those associated with convective uplift of boundary layer air, or tropopause folds. In the simplest sampling mode, now in use, samples are taken at regular intervals. The pumps are switched off between two samplings to reduce wear and to lessen the heat production. In the triggered mode, foreseen for the future, the pumps will be run continuously and the sampling will be triggered by signals from the ozone, $\mathrm{CO}$ or aerosol instruments. As in this case the sample air is flowing continuously through a canister, there is some degree of retrospective sampling. This means that when an event occurs and the system is triggered, sampling is already on its way. The amount of collected air should be sufficient for analyses of hydrocarbons, halocarbons, greenhouse gases and of the isotopic composition of $\mathrm{CO}_{2}$ (in the future also $\mathrm{CO}, \mathrm{CH}_{4}$, and $\mathrm{H}_{2}$ ). As the analyses are made using up to 5 different analytical instruments in 4 countries, altogether 3 sets of 2 sample canister units were built to secure the availability of one set for a monthly flight. Compared to the previous CARIBIC air sampler, the only trace compound that cannot be measured is the ultra low concentration tracer ${ }^{14} \mathrm{CO}$ which has an abundance of typically only 10 molecules per $\mathrm{cm}^{3}$ of air STP.

Glass is used for the construction of the canisters. Although this is technically somewhat more elaborate, its inertness has overriding advantages. Also due to its semi-liquid nature, the surface area is smallest. Another advantage of glass containers is that $\mathrm{CO}_{2}$ and its ${ }^{18} \mathrm{O}$ isotopic composition are less prone to changes.

The entire system consists of three units: a three stage pump unit and two canister units with 14 glass canisters each. Two metal bellow pumps (Model PWSC 28823-7, Senior Aerospace Inc., Sharon, Mass., U.S.A.), the first one with its two bellows in parallel as a first stage, and the second one with its bellows in series as the second and the third stage, are used to pressurize the air from the $200-250 \mathrm{hPa}$ inlet pressure to about 4 bar. These pumps as supplied by the manufacturers as potable water pumps for aircraft use actually have $0.5 \mathrm{~mm}$ holes drilled in the bellows' flanges presumably to automatically release pressure when not running. We sealed these small vent holes using washers with Viton orings. Mechanical pressure release valves (Nupro) are used to prevent over-pressurization. The 2.74 liter glass vessels (length $450 \mathrm{~mm}$, OD $100 \mathrm{~mm}$ ) are manufactured by Louwers Hapert Ltd. (Hapert, the Netherlands) from borosilicate glass tubing (Schott, $5 \mathrm{~mm}$ wall thickness), and rated for a pressure of 7 bar. The vessels are shielded with a polymer liner (thick heat shrink tubing) and housed inside a structure with 14 "pigeon holes" as shown in Fig. 12. They are connected to the inlet and outlet multiposition valves via stainless steel tubing which is cemented (Araldite 2020, Vantico AG, Basel, Switzerland) in two glass capillaries protruding into the cylindrical vessel at each end. Two 16 position Valco valves (VICI Valco Instruments Co. Inc., Schenkon, Switzerland) are used to switch between canisters. Prior to sampling the air in the cylinders is replaced $\sim 10$ times by continuously flushing. Usually all canisters are filled during the forward flight. During the return flight, half of them are vented and refilled. This procedure ensures that in case no sampling would take place during the homeward leg, the maximum number of samples is still obtained.

Sample analyses of over 250 samples collected until December 2006 show that some trace gases that are difficult to 
preserve in stainless steel canisters, such as alkyl nitrates and DMS, are preserved in the glass flasks. Further tests concerning the properties of glass for specific trace gases have to be carried out. It is furthermore noted that ozone is most likely lost in the pumping stage considering the temperatures of typically $50^{\circ} \mathrm{C}$ of the metal bellows. Some results of air sample analyses are illustrated in the flight overview of Fig. 9.

\subsection{Trace gas sampling using adsorption tubes}

Measurement of low level trace gases that cannot be collected with flasks because they are lost at surfaces is a challenge and the deployment of a PTRMS (Sect. 4.11) is one strategy. Another way to measure VOC and OVOCs is to preconcentrate them reversibly on substrates that do not absorb the abundant atmospheric gases and to perform post flight analyses. In the UT/LS the dryness of the air is conducive to adsorptive sampling, yet ozone may pose problems for sampling of some compounds.

A system based on 16 adsorption tubes for the determination of selected OVOCs was constructed (19", $5 \mathrm{HU}, 21 \mathrm{~kg})$. The sampler uses standard size Silcosteel tubes (3.5" long, $1 / 4$ " O.D., Restek, Bellefonte, PA, U.S.A.) that contain the adsorbent, presently Carbopack X. The tubes are located in channels in an aluminum block that is cooled by Peltier elements to a temperature of down to $-15^{\circ} \mathrm{C}$. The reason for cooling is to be able to select and maintain stable temperatures below the container temperature which may reach $25^{\circ} \mathrm{C}$.

The adsorption tubes are switched using two 16 position Valco valves (VICI Valco Instruments Co. Inc., Schenkon, Switzerland). The switching of the valves, the pump and the flow controller are controlled by the same V25 computer which also controls the whole air sampler. The unit functions well with research on recovery and interferences in progress.

\subsection{Video camera}

During CARIBIC phase \#1 particle events have been observed, often in association with strong convection. However, there was no information about the presence of clouds, because the old system did not have respective water sensors. In CARIBIC phase \#2 information on clouds can be gained not only by the fast water sensors (cf. 4.1), but also by a video camera, which observes the surrounding of the aircraft in forward direction. Another important function of the video camera is to check whether ice builds up on the leading edge of the shroud, which would influence the particle collection efficiency. Color images of $768 \times 494$ pixel resolution are recorded at a $2 \mathrm{~Hz}$ repetition rate and stored on a video recorder in the OPC unit in the container. An electronic shutter with $10^{-4} \mathrm{~s}$ time response prevents damaging of the CCD sensor in case of direct view into the sun. The images obtained show the presence of contrails, other aircraft, clouds, and the occasional occurrence of lightning (at night).

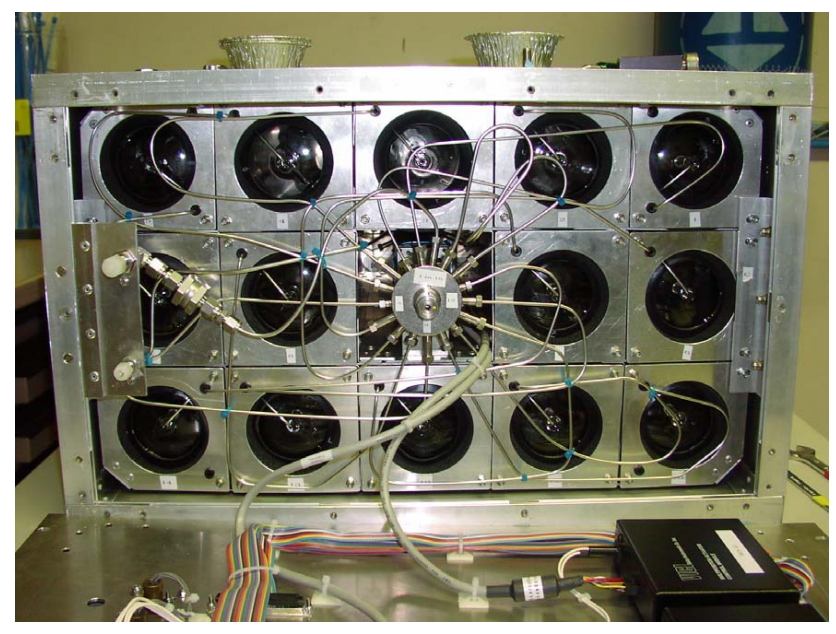

Fig. 12. Photo of one of the 6 whole air sampler units during construction without fron cover plate. Each sampler has two 16 multiposition valves (centre) attached to the 14 glass vessels. Two of the 16 positions on each valve are connected by $1 / 8^{\prime \prime}$ tubing.

\subsection{DOAS based remote sensing}

The DOAS (Differential Optical Absorption Spectroscopy) instrument adds an important remote sensing capability to CARIBIC. The system is small, has no moving parts and analyses certain trace gases (e.g. $\mathrm{HONO}$ and $\mathrm{BrO}$ ) that are otherwise not detectable. The absence of moving parts, the remote capability and the compactness of the DOAS experiment renders it potentially extremely useful for CARIBIC type of applications. The DOAS instrument consists of two parts: a telescope block integrated in the pylon of the inlet system, and three spectrograph-detector units located in the container instrument (19", $3 \mathrm{HU}, 16 \mathrm{~kg}$ ). Quartz fiber cables transmit the light from the telescopes to the detectors in the container.

Each spectrograph-detector unit records spectra of scattered sun light in the UV-visible range, from one of the respective three different viewing directions (nadir, $10^{\circ}$ above, and below the horizon). After each flight the recorded spectra are analyzed using the well known DOAS technique (Platt et al., 1979; Platt, 1994; Solomon et al., 1987) by which various trace gases (e.g., halogen oxides, $\mathrm{O}_{3}, \mathrm{NO}_{2}$ ) can be assayed by means of their individual absorption structures. The different viewing directions of the telescopes (MultiAxis DOAS) yield additional information on the distribution of the trace gases above and below the aircraft (see also Heue et al., 2005). The continuation of measurements during ascent and descent of the aircraft allow the reconstruction of vertical profiles of the respective trace gases. Due to the sun being the source of scattered light, the DOAS technique gives data only during local daytime (can be as low as $50 \%$ of the flight time).

The three Ocean Optics USB 2000 spectrometers are 


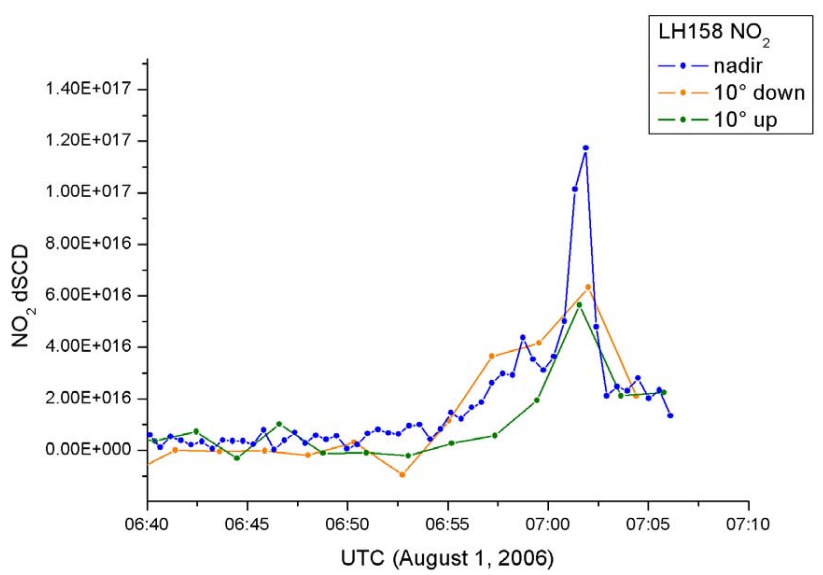

Fig. 13. A typical DOAS result upon landing in Guangzhou, China. All viewing directions show a rising slant column of $\mathrm{NO}_{2}$ at 06:55 UTC, when the airplane is just inside the boundary layer at a height of about $2.3 \mathrm{~km}$. The different sensitivities of the viewing directions can be used to model the light paths and the aerosol load inside the boundary layer in order to derive the local $\mathrm{NO}_{2}$ concentration profile.

custom made miniature spectrographs (with a wavelength range of $280-420 \mathrm{~nm}$ ) which include a one-dimensional CCD-detector with 2048 pixel. The spectrographs are temperature stabilized using Peltier elements. The simultaneous measurements of the three spectrograph devices are controlled by a single computer ( $10 \mathrm{~W}$ power consumption). Spectra are typically recorded every $30 \mathrm{~s}$. With this time resolution optical densities in the order of $0.1 \%$ can be detected. By adding up spectra, the detection limit can be improved by a factor of 2 . Since the measured optical density depends strongly on the length of the light paths within the trace gas layer and on the individual absorption cross section, no general detection limits for trace gas concentrations can be given. For a tropospheric $\mathrm{BrO}$ background with a vertical column density of $1 \times 10^{13}$ molecule $\mathrm{cm}^{-2}$ and a $3 \mathrm{ppt}$ maximum at $6 \mathrm{~km}$ altitude (Fitzenberger et al., 2000), with no aerosols present, a time resolution of $7.5 \mathrm{~min}$, and a solar zenith angle of $20^{\circ}$, the detection limit would be $2.8 \mathrm{ppt}$ for the $10^{\circ}$ down viewing direction.

The telescope block $\left(13.5 \times 6.7 \times 1.5 \mathrm{~cm}^{3}\right)$ is mounted inside the pylon of the inlet system. Incoming light (aperture $\left.1.5^{\circ}\right)$ is reflected over $90^{\circ}$ by quartz prisms $(5 \times 5 \mathrm{~mm})$ and then focused by a quartz lens ( $\mathrm{f}=15 \mathrm{~mm}$ ) on 4 quartz fibers $(200 \mu \mathrm{m})$ inside a cable. To reduce instrumental stray light a band pass filter (UG 5) is placed on the lens. The glass fiber cables are connected to the telescopes by 1/16" Swagelok U1tra Torr adapters. At the telescope side the 4 quartz fibers are arranged circularly to adjust to the focus of the lens whereas at the other end the fibers are set up in a line to adapt to the entrance slit of the spectrograph. During flights, the telescope block is heated with three heating pads $(15 \mathrm{~W}$ unregu- lated) to avoid freezing of water on the outside surface of the prisms. Furthermore, each telescope unit is vacuum sealed to prevent condensation of water vapor. The DOAS system functions, although the light yield from the two limb channels has become low. An example of $\mathrm{NO}_{2}$ data obtained from DOAS measurements is shown in Fig. 13.

\section{Operation}

Prior to the monthly series of measurement flights (for instance to Manila via Guangzhou and back to Frankfurt via Guangzhou) all equipment is checked, communications are tested, gas supplies are refreshed, the system is leak tested and the overall operation is checked. For this purpose a large power supply of $400 \mathrm{~Hz}, 115 \mathrm{~V}$ is available. After lifting the hydraulic platform the container is loaded in the institute's truck. At Frankfurt airport the container is installed into the forward cargo bay and carefully connected to the aircraft by avionic personnel in attendance of scientists. After enabling the power circuits and a final power and system test the container doors are closed and the system is ready for the 2 days unattended flying with 3 stops of about $2 \mathrm{~h}$ in Guangzhou and Manila. After the installation regular airfreight is loaded and the cargo bay temperature is set at $10^{\circ} \mathrm{C}$. The actual container temperature in flight reaches about $30^{\circ} \mathrm{C}$. The installation of all connections follows a strict procedure but is completed within $20 \mathrm{~min}$. Upon return a similar procedure for de-installation is followed.

After a flight the measurement data and diagnostic data are recovered by extracting the various memory cards. Furthermore, the 2 air sample containers and the aerosol sample unit are removed for analyses in the laboratories. The performance of the temperature control (16 regulated heaters) is tested using a dummy inlet/tubing heating system.

\section{Conclusions}

The first generation of CARIBIC demonstrated that valuable measurements of more than 50 atmospheric trace species including aerosol particles can be made using a freight container equipped with automated instruments onboard a commercial airliner. Regular measurement flights at a rate of one flight per month were achieved over period from the November 1997 to April 2002. The project was terminated because of the change of aircraft fleet.

The second generation of CARIBIC in ongoing operation since 2005, significantly extends the measurement capability by using improved instruments, by adding instruments for $\mathrm{CO}_{2}, \mathrm{O}_{2}, \mathrm{Hg}, \mathrm{H}_{2} \mathrm{O}$, selected organic compounds (PTRMS), accumulation mode particles, as well as $\mathrm{NO}_{2}, \mathrm{BrO}$ and other atmospheric trace gases (MAX-DOAS), and of a video camera. In addition, the sampling capabilities were enhanced: the number of air and aerosol samples per flight was substantially increased and sampling of volatile organic compounds 
on adsorption tubes was added. The post-flight analysis of impactor samples is under improvement using PESA.

The two years of operation of CARIBIC with a new airline company, using a new Airbus A340-600, with a new container and a new sophisticated inlet system convincingly show in more than 80 individual flights that the approach of detailed monitoring of atmospheric composition by passenger aircraft, thus forming an "automated flying analytical observatory", is well feasible.

Concerning the operation of the CARIBIC system there is a need for further improvements. Foremost is the improvement in the reliability of the equipment. While the air sampler, the $\mathrm{CO}$ and $\mathrm{Hg}$ analyzers have attained a figure of merit of over $90 \%$, some systems have not reached this level yet. We emphasize that unlike research aircraft, CARIBIC with currently 15 experiments on board has to perform unattended for days at a stretch. This requires a high degree of reliability of the equipment which means that in the course of time improvements are necessary in equipment design, construction and electronics. We consider this as a high priority. While gaining more experience, all equipment is increasingly performing failure free, but investments in new, improved equipment is needed. Another or additional strategy could be the implementation of a communication system, for instance real time control of equipment from the ground. However, experience shows that the most effective measure is improving equipment. By doing this, CARIBIC will become a fully operational tool.

Two important issues are the quality control of the data and the possibility of in flight comparisons with other aircraft measurements. The basis of CARIBIC is that the partaking institutions have expert knowledge concerning their measurements in CARIBIC. Years of experience in these institutions with given measurements with fairly identical equipment under a wide range of conditions and the pre and post flight checks are the main basis for obtaining quality data. For instance the aerosol measurements of the current system are very comparable to the data of the previous CARIBIC system that used a much different inlet system. In flight comparisons with other aircraft will remain a rare opportunity, yet the upcoming operation of the German research aircraft HALO (www.halo.dlr.de) may allow direct comparisons.

The container concept also allows for modifications and extensions of the scientific payload. One issue is the detection of $\mathrm{NO}_{2}$. Here the development of UV light emitting diodes offers the possibility of adding a photolysis reactor without needing substantial amounts of added electrical power. High on the list of priorities is the measurement of $\mathrm{SO}_{2}$. The scope of saving weight and space and minimizing power consumption, in particular by the pumping systems, together with current developments of sufficiently sensitive $\mathrm{SO}_{2}$ systems based on chemical ionization mass spectrometry render this tangible. Beyond this, also developments in particle mass spectrometry are promising, thus offering another important extension of analytical capabilities of the flying laboratory.

CARIBIC can contribute substantially to the research on atmospheric chemistry and climate change now and in the future by filling the gaps between satellite based remote sensing, land based observatories, and research aircraft based campaigns. With the vastly improved atmospheric chemistry models available to date, systematic and detailed information will be essential for their evaluation and further development.

Acknowledgements. We thank Lufthansa Airlines and Lufthansa Technik for their commitment and support. Without the help of many individuals in various organizations this advanced version of CARIBIC could not have become reality. The development and operation of CARIBIC has been financially supported by the German Ministry of Education and Science (AFO 2000), by the European Commission's DGXII Environment RTD 4th and 5th Framework programs, by grants from the Max Planck Society and from EON-Ruhrgas.

Edited by: J.-L. Jimenez

\section{References}

An, W. J., Pathak, R. K., Lee, B.-H., and Pandis, S. N.: Aerosol volatility measurements using an improved thermodenuder: Application to secondary organic aerosol, J. Aerosol Sci. 38, 305314, 2007.

Bischof, W.: Carbon dioxide measurements from aircraft, Tellus, 22, 545-549, 1970.

Bozóki, Z., Sneider, J., Gingl, Z., Mohásci, A., Szakáll, M., Bor, Z., and Szabó, G.: A high-sensitivity, near-infrared tunable-diodelaser-based photoacoustic water-vapour-detection system for automated operation, Meas. Sci. Technol., 10, 999-1003, 1999.

Bozóki, Z., Szakáll, M., Mohásci, A., Szakáll, M., Szabó, G., and Bor, Z.: Diode laser based photoacoustic humidity sensors, Sens. Actuators, B 91, 219-226, 2003.

Brenninkmeijer, C. A. M., Crutzen, P. J., Fischer, H., Güsten, H., Hans, W., Heinrich, G., Heintzenberg, J., Hermann, M., Immelmann, T., Kersting, D., Maiss, M., Nolle, M., Pitscheider, A., Pohlkamp, H., Scharffe, D., Specht, K., and Wiedensohler, A.: CARIBIC - civil aircraft for global measurement of trace gases and aerosols in the tropopause region, J. Atmos. Oceanic Technol., 16, 1373-1383, 1999.

Brough, N., Reeves, C., Penkett, S. A., Dewey, K., Kent, J., Barjat, H., Monks, P.S., Ziereis, H., Stock, P., Huntrieser, H., and Schlager, H.: Intercomparison of aircraft instruments on board the C-130 and Falcon 20 over southern Germany during EXPORT 2000, Atmos. Chem. Phys., 3, 2127-2138, 2003, http://www.atmos-chem-phys.net/3/2127/2003/.

Brunner, D., Staehelin, J., Jeker, D., Wernli, H., and Schumann, U.: Nitrogen oxides and ozone in the tropopause region of the northern hemisphere: measurements from commercial aircraft in 1995/1996 and 1997, J. Geophys. Res., 106, 27 673-27 699, 2001.

Connors, V. S., Cahoon, D. R., Reichle, H. G., Jr., and Scheel, H. E.: Comparison between carbon monoxide measurements from 
spaceborne and airborne platforms, Can. J. Phys., 69, 11281137, 1991.

Crutzen, P. J., Elansky, N. F., Hahn, M., Golitsyn, G. S., Brenninkmeijer, C. A. M., Scharffe, D. H., Belikov, I. B., Maiss, M., Bergamaschi, P., Röckmann, T., Grisenko, A. M., and Sevostyanov, V. M.: Trace gas measurements between Moscow and Vladivostok using the Trans-Siberian railroad, J. Atmos. Chem. 29, 179-194, 1998.

De Gouw, J., Warneke, C., Holzinger, R., Klüpfel, T., and Williams, J.: Intercomparison between airborne measurements of methanol, acetonitrile and acetone using two differently configured PTR-MS instruments, Int. J. Mass Spectrometry, 239, 129-137, 2004.

Dickerson, R. R.: Measurements of reactive nitrogen compounds in the free troposphere, Atmos. Environ., 18, 2585-2593, 1984.

Ebinghaus, R. and Slemr, F.: Aircraft measurements of atmospheric mercury over southern and eastern Germany, Atmos. Environ., 34, 895-903, 2000.

Ebinghaus, R., Slemr, F., Brenninkmeijer, C. A. M., van Velthoven, P., Zahn, A., Hermann, M., Oram, D. E., and O'Sullivan, D.: Emissions of gaseous mercury from biomass burning in South America in 2005 observed during CARIBIC flights, Geophys. Res. Lett., 34, doi:10.1029/2006GL028866, 2007.

Fabian, P. and Pruchniewicz, P. G.: Meridional distribution of ozone in the troposphere and its seasonal variations, J. Geophys. Res., 82, 2063-2073, 1977.

Falconer, P. D. and Holdeman, J. D.: Measurements of atmospheric ozone made from a GASP-equipped 747 airliner: mid March, 1975, Geophys. Res. Lett., 3, 101-104, 1976.

Fitzenberger, R., Bösch, H., Camy-Peyret, C., Chipperfield, M., Harder, H., Platt, U., Sinnhuber, B.-M., Wagner, T., and Pfeilsticker, K.: First profile measurement of tropospheric BrO, Geophys. Res. Lett., 27, 2921-2924, 2000.

Foulger, B. E. and Simmonds, P. G.: Ambient temperature gas purifier suitable for the trace analysis of carbon monoxide and hydrogen and the preparation of low-level carbon monoxide calibration standards in the field, J. Chromatog., 630, 257-263, 1993.

Gerbig, C., Kley, D., Volz-Thomas, A., Kent, J., Dewey, K., and McKenna, D.S.: Fast-response resonance fluorescence CO measurements aboard the C-130: Instrument characterization and measurements made during NARE '93, J. Geophys. Res., 101, 29229-29238, 1996.

Gerbig, C., Schmitgen, S., Kley, D., Volz-Thomas, A., Dewey, K., and Haaks, D.: An improved fast-response vacuum-UV resonance fluorescence CO instrument, J. Geophys. Res., 104, 1699$1704,1999$.

Güsten, H., Heinrich, G., Schmidt, R. W. H., and Schurath, U.: A novel ozone sensor for direct eddy flux measurements, J. Atmos. Chem., 14, 73-84, 1992.

Hansel, A., Jordan, A., Warneke, C., Holzinger, R., Wisthaler, A., and Lindinger, W.: Proton-transfer-reaction mass spectrometry (PTR-MS): on-line monitoring of volatile organic compounds at volume mixing ratios of a few pptv, Plasma Sources Sci. Technol., 8, 332-336, 1999.

Heintzenberg, J., Hermann, M., Martinsson, B. G., and Papaspiropoulos, G.: Number and sulfur derived 3-parameter aerosol size distributions in the tropopause region from CARIBIC flights between Germany and the Indic, J. Aerosol Sci., 33, 595-608, 2002.
Heintzenberg, J., Hermann, M., and Theiss, D.: Out of Africa: High aerosol concentrations in the upper troposphere over Africa, Atmos. Chem. Phys., 3, 1191-1198, 2003, http://www.atmos-chem-phys.net/3/1191/2003/.

Hermann, M., Stratmann, F., Wilck, M., and Wiedensohler, A.: Sampling characteristics of an aircraft-borne aerosol inlet system, J. Atmos. Oceanic Technol., 18, 7-19, 2001.

Hermann, M. and Wiedensohler, A.: Counting efficiency of condensation particle counters at low-pressures with illustrative data from the upper troposphere, J. Aerosol Sci., 32, 975-99, 2001.

Hermann, M., Heintzenberg, J., Wiedensohler, A., Zahn, A., Heinrich, G., and Brenninkmeijer, C.A.M.: Meridional distributions of aerosol particle number concentrations in the upper troposphere and lower stratosphere obtained by Civil Aircraft for Regular Investigation of the Atmosphere Based on an Instrument Container (CARIBIC) flights. J. Geophys. Res., 108, No. D3, 4114-4130, doi:10.1029/2001JD001077, 2003.

Heue, K.-P , Richter, A., Bruns, M., Burrows, J.P., von Friedeburg, C., Platt, U., Pundt, I., Wang, P., and Wagner, T.: Validation of SCIAMACHY tropospheric $\mathrm{NO}_{2}$ columns with AMAXDOAS measurements, Atmos. Chem. Phys., 5, 1039-1051, 2005, http://www.atmos-chem-phys.net/5/1039/2005/.

Hurst, D. F., Romashkin, P. A., Elkins, J. W., Oberländer, E. A., Elansky, N. F., Belikov, I. B., Granberg, I. G., Golitsyn, G. S., Grisenko, A. M., Brenninkmeijer, C. A. M., and Crutzen, P. J.: Emissions of ozone-depleting substances in Russia during 2001, J. Geophys. Res., 109, D14, D14303, doi:10.1029/2004JD004633, 2004.

Joeckel, P.: Cosmogenic ${ }^{14} \mathrm{CO}$ as Tracer for Atmospheric Chemistry and Transport. Ph.D. Thesis, 347, University of Heidelberg, 2000.

Krol, M. C., Lelieveld, J., Oram, D. E., Sturrock, G. A., Penkett, S. A., Brenninkmeijer, C. A. M., Gros, V., Williams, J., and Scheeren, H. A.: Continuing emissions of methylchloroform from Europe, Nature, 421, 131-135, 2003.

Lelieveld, J., van Aardenne, J., Fischer, H., de Reus, M., Williams, J., and Winkler, P.: Increasing ozone over the Atlantic Ocean, Science, 304, 1483-1487, 2004.

Lindinger, W., Hansel, A., and Jordan, A.: On-line monitoring of volatile organic compounds at ppt-levels by means of protontransfer-reaction mass spectrometry (PTR-MS): Medical applications, food control and environmental research, Int. J. Mass Spectrom. Ion Processes, 173, 191-241, 1998.

Liu, B. Y. H., Zhang, Z. Q., and Kuehn, T. H.: A numerical study of inertial errors in anisokinetic sampling, J. Aerosol Sci., 20, 367-380, 1989.

Marenco, A., Thouret, V., Nédélec, P., Smit, H., Helten, M., Kley, D., Karcher, F., Simon, P., Law, K., Pyle, J., Poschmann, G., Von Wrede, R., Hume, C., and Cook, T.: Measurement of ozone and water vapor by Airbus in-service aircraft: The MOZAIC airborne program, an overview, J. Geophys. Res., 103, 25 631-25 642, 1998.

Martinsson, B. G., Frank, G., Cederfelt, S.-I., Berg, O. H., Mentes, B., Papaspiropoulos, G., Swietlicki, E., Zhou, J., Flynn, M., Bower, K. N., Choularton, T. W., Mäkelä, J., Virkkula, A., and van Dingenen, R.: Validation of very high cloud droplet number concentrations in air masses transported thousands of kilometers over the ocean, Tellus 52B, 801-814, 2000.

Martinsson, B. G., Papaspiropoulos, G., Heintzenberg, J., and Her- 
mann, M.: Fine mode particulate sulphur in the tropopause region measured from intercontinental flights (CARIBIC), Geophys. Res. Lett., 28, 1175-1178, 2001.

Martinsson, B. G., Nguyen, H. N., Brenninkmeijer, C. A. M., Zahn, A., Heintzenberg, J., Hermann, M., and van Velthoven, P. F. J.: Characteristics and origin of lowermost stratospheric aerosol at northern midlatitudes under volcanically quiescent conditions based on CARIBIC observations, J. Geophys. Res., 110, D12201, doi:10.1029/2004JD005644, 2005.

Matsueda, $\mathrm{H}$. and Inoue, $\mathrm{H}$. Y.: Measurements of atmospheric $\mathrm{CO}_{2}$ and $\mathrm{CH}_{4}$ using a commercial airliner from 1993 to 1994, Atmos. Environ., 30, 1647-1655, 1996.

Montzka, S. A. and Fraser, P. J.: Controlled substances and other source gases, in: Scientific Assessment of Ozone Depletion: 2002, Global Ozone Research and Monitoring Project, vol. 47, edited by: Ennis, C. A., chap. 1, pp.1.1-1.83, World Meteorol. Org., Geneva Switzerland, 2003.

Mühle, J., Brenninkmeijer, C.A. M., Rhee, T. S., Slemr, F., Oram, D. E., Penkett, S. A., and Zahn, A.: Biomass burning and fossil fuel signatures in the upper troposphere observed during a CARIBIC flight from Namibia to Germany, Geophys. Res. Lett., 29, No.19, 1910, doi:10.1029/2002GL015764, 2002.

Murphy, D. M. and Schein, M. E.: Wind tunnel tests of a shrouded aircraft inlet, Aerosol Sci. Technol. 28, 33-39, 1998.

Murphy, D. M., Cziczo, D. J., Hudson, P. K., Thomson, D. S., Wilson, J. C., Kojima, T., and Buseck, P. R.: Particle generation and resuspension in aircraft inlets when flying in clouds, Aerosol Sci. Technol. 38, 400-408, 2004.

Murphy, D. M., Cziczo, D. J., Froyd, K. D., Hudson, P. K., Matthew, B. M., Middlebrook, A. M., Peltier, R. E., Sullivan, A., Thomson, D. S., and Weber, R. J.: Single-particle mass spectrometry of tropospheric aerosol particles, J. Geophys. Res., 111, D23S32, doi:10.1029/2006JD007340, 2006.

Nastrom, G. D.: Ozone in the upper troposphere from the GASP measurements, J. Geophys. Res., 84, 25 631-25 642, 1979.

Neuman, J. A., Huey, L. G., Ryerson, T. B., and Fahey, D. W.: Study of inlet materials for sampling atmospheric nitric acid, Environ. Sci. Technol. 33, 1133-1136, 1999.

Nguyen, H. N., Gudmundsson, A., and Martinsson, B. G.: Design and calibration of a multi-channel aerosol sampler for studies of the tropopause region from the CARIBIC platform, Aerosol Sci. Technol. 40, 649-655, 2006.

Nguyen, H. N. and Martinsson, B. G.: Analysis of C, N,and O in aerosol collected on an organic backing using internal blank measurements and variable beam size, Nuclear Instrum. Methods in Phys Res. B, in press, 2007.

Papaspiropoulos G., Mentes, B., Kristiansson, P., and Martinsson, B. G.: A high sensitivity elemental analysis methodology for upper tropospheric aerosol, Nucl. Instr. Meth., B150, 356-362, 1999.

Papaspiropoulos, G., Martinsson, B. G., Zahn, A., Brenninkmeijer, C. A. M., Hermann, M., Heintzenberg, J., Fischer, H., and van Velthoven, P. F. J.: Aerosol elemental concentrations in the tropopause region from intercontinental flights with the CARIBIC platform, J. Geophys. Res., 107, D23, 4671, doi:10.1029/2002JD002344, 2002.

Peylin, P., Bréon, F. M., Serrar, S., Tiwari, Y, Chédin, A., Gloor, M., Machida, T., Brenninkmeijer C.A.M. , Zahn A., and Ciais, P.: Evaluation of Television Infrared observation Satellite (TIROS-
N) Operational Vertical Sounder (TOVS) spaceborne CO2 estimates using model simulations and aircraft data, J. Geophys. Res. 112, D09313, doi:10.1029/2005JD007018, 2007.

Platt, U., Perner, D., and Pätz, H. W.: Simultaneous measurement of atmospheric $\mathrm{CH}_{2} \mathrm{O}, \mathrm{O}_{3}$, and $\mathrm{NO}_{2}$ by differential optical absorption, J. Geophys. Res., 84, 6329-6335, 1979.

Platt, U.: Differential optical absorption spectroscopy (DOAS), in: Monitoring by Spectroscopic Techniques, edited by: Sigrist, M. W., John Wiley, New York, 1994.

Pratt, R. and Falconer, P.: Circumpolar measurements of ozone, particles, and carbon monoxide from a commercial airliner, J. Geophys. Res., 84, 7876-7882, 1979.

Prinn, R. G., Weiss, R. F., Fraser, P. J., Simmonds, P. G., Cunnold, D. M., Alyea, F. N., O’Doherty, S., Salameh, P., Miller, B. R., Huang, J., Wang, R. H. J., Hartley, D. E., Harth, C., Steele, L. P., Sturrock, G., Midgley, P. M., and McCulloch, A.: A history of chemically and radiatively important gases in air deduced from ALE/GAGE/AGAGE, J. Geophys. Res., 105, 17 751-17 792, 2000.

Pupek, M., Assonov, S. S., Mühle, J., Rhee, T. S., Oram, D., Koeppel, C., Slemr, F., and Brenninkmeijer, C. A. M.: Isotope analysis of hydrocarbons: Trapping, recovering and archiving hydrocarbons and halocarbons separated from ambient air, Rapid Commun. Mass Spectrometry, 19, 455-460, 2005.

Reichelt, M.: Entwicklung und atmosphärische Anwendung eines optischen Partikelzählers für Tropopausenbedingungen, Ph.D. thesis, University of Leipzig, 306, 2007.

Rhee, T. S., Brenninkmeijer, C. A. M., and Röckmann, T.: The overwhelming role of soils in the global atmospheric hydrogen cycle, Atmos. Chem. Phys. 6, 1611-1625, 2006.

Schwarzenböck A., Heintzenberg, J., and Mertes, S.: Incorporation of aerosol particles between 25 and $850 \mathrm{~nm}$ into cloud elements: measurements with a new complementary sampling system, Atmos. Res. 52, 241-260, 2000.

Seiler, W. and Junge, C.: Decrease of carbon monoxide mixing ratio above the polar tropopause, Tellus, 21, 447-449, 1969.

Seiler, W. and Junge, C.: Carbon monoxide in the atmosphere, J. Geophys. Res., 75, 2217-2226, 1970.

Singh, H. B., Kanakidou, M., Crutzen, P. J., and Jacob; D. J.: High concentrations and photochemical fate of oxygenated hydrocarbons in the global troposphere, Nature 378, 50-54, 1995.

Singh, H. B., Salas, L. J., Chatfield, R. B., Czech, E., Fried, A., Walega, J., Evans, M. J., Field, B. D., Jacob, D. J., Blake, D., Heikes, B, Talbot, R., Sachse, G., Crawford, J. H., Avery, M. A., Sandholm, S., and Fuelberg, H.: Analysis of the atmospheric distribution, sources, and sinks of oxygenated volatile organic chemicals based on measurements over the Pacific during TRACE-P, J. Geophys. Res. 109, D15S07, doi:10.1029/2003JD003883, 2004.

Slemr, F., Seiler, W., Eberling, C., and Roggendorf, P.: The determination of total gaseous mercury in air at background levels, Anal. Chim Acta, 110, 35-47, 1979.

Solomon, S. A., Schmeltekopf, A. L., and Sanders, R. W.: On the interpretation of zenith sky absorption measurements, J. Geophys. Res., 92, 8311-8319, 1987.

Stanier, C. O., Pathak, R. K., and Pandis, S. N.: Measurements of the volatility of aerosols from a-pinene ozonolysis, Environ. Sci. Technol. 41, 2756-2763, 2007.

Sturges, W. T., Oram, D. E., Carpenter, L. J., Penkett, S. A., and En- 
gel, A.: Bromoform as a source of stratospheric bromine, Geophys. Res. Lett., 27, 2081-2084, 2000.

Szakáll, M., Bozóki, Z., Kraemer, M., Spelten, N., Möhler, O., and Schurath, U.: Evaluation of a photoacoustic detector for water vapor measurements under simulated tropospheric/lower stratospheric conditions, Environ. Sci. Technol., 35, 4881-4885, 2001.

Temme, C., Einax, J.W., Ebinghaus, R., and Schroeder, W.H.: Measurements of atmospheric mercury species at a coastal site in the Antarctic and over the South Atlantic Ocean during polar summer, Environ. Sci. Technol., 37, 22-31, 2003.

Tiefenau, H. K., Pruchniewicz, P. G., and Fabian, P.: Meridional distribution of tropospheric ozone from measurements aboard commercial airlines, Pure Appl. Geophys., 106-108, 1036-1040, 1973.

Volz, A. and Kley, D.: A resonance fluorescence instrument for the in-situ measurement of atmospheric carbon monoxide, J. Atmos. Chem., 2, 345-357, 1985.

Volz-Thomas, A., Berg, M., Houben, N., Petrick, W., Raak, D., and Pätz, H.-W.: Measurements of total odd nitrogen $\left(\mathrm{NO}_{y}\right)$ aboard MOZAIC in-service aircraft: instrument design, operation and performance, Atmos. Chem. Phys. 5, 583-595, 2005.

Wilson, K.L. and Birks, J.W.: Mechanism and elimination of a water vapor interference in the measurement of ozone by uv absorbance, Environ. Sci. Technol., 40, 6361-6367, 2006.

WMO (World Meteorological Organization):The Changing Atmosphere: An Integrated Global Atmospheric Chemistry Observation Theme for the IGOC Partnership, WMO/ GAW report No. 159 (WMO TD No. 1235), Geneva, Switzerland, 2004.

Zahn, A, Brenninkmeijer, C. A. M., Maiss, M., Scharffe, D. H., Crutzen, P. J., Hermann, M., Wiedensohler, A., Heintzenberg, J., Güsten, H., Heinrich, G., Fischer, H., Cuijpers, J. W. M., and van Velthoven, P. F. J.: Identification of extratropical two-way troposphere-stratosphere mixing based on CARIBIC measurements of $\mathrm{O}_{3}, \mathrm{CO}$, and ultrafine particles, J. Geophys. Res., 105, $1527-1535,2000$.
Zahn, A., Brenninkmeijer, C. A. M., Asman, W. A. H., Crutzen, P. J., Heinrich, G., Fischer, H., Cuijpers, J. W. M., and van Velthoven, P. F. J.: The budgets of $\mathrm{O}_{3}$ and $\mathrm{CO}$ in the upper troposphere: CARIBIC passenger aircraft results 1997-2001, J. Geophys. Res., 107, D17, 4337, doi:10.1029/2001JD001529, 2002a.

Zahn, A., Brenninkmeijer, C. A. M., Crutzen, P. J., Parrish, D. D., Sueper, D., Heinrich, G., Güsten, H., Fischer, H., Hermann, M., and Heintzenberg, J.: Electrical discharge source for tropospheric "ozone-rich transients", J. Geophys. Res., 107, D22, 4638, doi:10.1029/2002JD002345, 2002b.

Zahn, A. and Brenninkmeijer, C. A. M.: New directions: a chemical tropopause defined, Atmos. Environ., 37, 439-440, 2003.

Zahn, A., Brenninkmeijer, C. A. M., and van Velthoven, P. F. J.: Passenger aircraft project CARIBIC 1997-2002, Part I: The extratropical chemical tropopause, Atmos. Chem. Phys. Discuss., 4, 1091-1117, 2004a.

Zahn, A., Brenninkmeijer, C. A. M., and van Velthoven, P. F. J.: Passenger aircraft project CARIBIC 1997-2002, Part II: The ventilation of the lowermost stratosphere, Atmos. Chem. Phys. Discuss., 4, 1119-1150, 2004b.

Ziereis, H., Schlager, H., and Schulte, P.: NO, $\mathrm{NO}_{\mathrm{y}}$, and $\mathrm{O}_{3}$ intercomparisons during POLINAT 2, in: Pollution from Aircraft Emissions in the North Atlantic Flight Corridor (POLINAT 2), Air. Pollut. Res. Rep. 68, edited by: U. Schumann, pp. 55-63, Eur. Comm., Luxembourg., 1999.

Ziereis, H., Schlager, H., Schulte, P., van Velthoven, P. F. J., and Slemr, F.: Distributions of $\mathrm{NO}, \mathrm{NO}_{\mathrm{x}}$, and $\mathrm{NO}_{\mathrm{y}}$ in the upper troposphere and lower stratosphere between $28^{\circ}$ and $61^{\circ} \mathrm{N}$ during POLINAT 2, J. Geophys. Res., 105, 3653-3664, 2000. 